\title{
Integration of Optimum Power for Wind Turbine Blade at Different Cross Section
}

\author{
Muhammad .A.R Yass Saadi Turied Kurdi Mahmood Abdulzahra Shkara \\ Electromechanical Department, University of Technology, Baghdad, Iraq \\ mohd.yass97@gmail.com drsadijohary@gmail.com mahmoodsem@yahoo.com
}

\begin{abstract}
This research analysis and optimizes the main wind horizontal turbine blade parameters for high-performance altitude with variable pitch blade angle for different blade cross-section unsymmetrical airfoil NACA 4412 and unsymmetrical airfoil supercritical Eppler 417. For deep specification, some wind horizontal turbine parameters kept constant through the proses method to integrate the highest behavior of windmill turbine power coefficient. The procedure analysis with FORTRAN.90 code , then compare with German code and then optimized using Schmitz and Betz method for blade chord and lift to drag for blade pitch angle. From theoretical results discussion, important conclusions figured; also a recommendation for further work was suggested. Best optimization methods were Schmitz chord optimization and Lift/Drag twist optimization which increases the Cp 10.3\% for Eppler 4417 and 9.5\% for NACA 4412.All results were tabulated and plotted for all optimization results
\end{abstract}

Keywords: Optimal Design, Algorithms, Betz Schmitz Lift/ Drag optimization, Wind Power, Computational Fluid Dynamics, Aerodynamic.

\begin{tabular}{|c|c|c|}
\hline Symbol & Definition & Uints \\
\hline$a$ & Interference factor & $\ldots .$. \\
\hline$a^{\prime}$ & Tangential Interference & $\cdots \cdot$. \\
\hline$B$ & No of Blade & $\ldots \ldots$ \\
\hline$C$ & Chord Length & $m$ \\
\hline$P$ & Power & watts \\
\hline$r$ & Radius & $m$ \\
\hline$U$ & Wind Speed & $\mathrm{m} / \mathrm{sec}$ \\
\hline$u$ & Axial Speed & $\mathrm{m} / \mathrm{sec}$ \\
\hline$v$ & Normal Speed & $\mathrm{m} / \mathrm{sec}$ \\
\hline$n$ & Rotational Speed & $1 / \mathrm{sec}$ \\
\hline$n$ & Rotational Speed & $1 / \sec$ \\
\hline$\Omega$ & Angular Speed & $\mathrm{Rad} / \mathrm{Sec}$ \\
\hline$\lambda$ & Tip Speed Ratio & .......... \\
\hline$\varphi$ & Setting Angle & deg \\
\hline$Q_{P}$ & Pitch Angle & deg \\
\hline$Q$ & Torque & $N / m$ \\
\hline $\mathrm{Cl}$ & lift coefficient & f....... \\
\hline$C p$ & Power Coefficient & $\ldots \ldots \ldots$ \\
\hline$\rho$ & density & $\mathrm{kg} / \mathrm{m}^{3}$ \\
\hline$\alpha$ & e of Attack & deg \\
\hline
\end{tabular}




\section{Mathematical Analysis}

The analysis is used for blade element and momentum theory. Momentum theory refers to the forces at the blade based on the conservation of angular and linear momentum. Blade element theory refers to an analysis of forces at a blade section. The results of this approximation can be combined into blade element momentum (BEM) theory. This theory can be used to calculate the extract power from the wind [1].

\subsection{Momentum theory}

By considering conservations of momentum, forces which are the rate of change of momentum the forces on a wind turbine blade and flow conditions at the blades can be derived. The axial and angular induction factors are assumed to be functions of the radius, $\boldsymbol{r}$. The conservation of linear momentum to the control volume of radius $\boldsymbol{I}$ and thickness $\mathrm{dr}$ is an expression for the differential contribution to the thrust [2]:

$$
d T=\rho U^{2} 4 a(1-a) \pi r d r
$$

And the differential torque, $\mathrm{Q}$, is:

$$
d Q=4 a^{\prime}(1-a) \rho U \pi r^{3} \Omega d r
$$

Equations (1) and (2), are defined the thrust and torque on an annular section of the rotor. [3].

\subsection{Blade Element Theory}

The function of lift and drag coefficients as wall as the angle of attack are expression to the forces on the blades of a wind turbine. As illustrated in Figure (1), for this analysis, the blade is assumed to be separated into $N$ elements. Where the following assumptions are made:

*there is no interaction between elements

*the forces on the blades are determined by the lift and drag property of the airfoil shape of the blades [4]

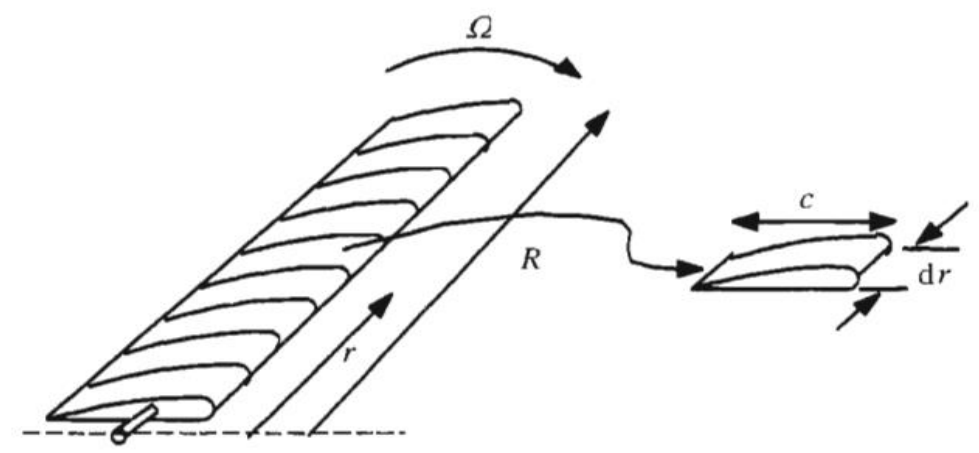

Figure (1):- Schematic of blade elements. fig source [4] 
In analyzing the forces on the blade section, it must note that the lift is perpendicular and drag forces is parallel to the relative wind. The relative wind is the vector resulted from the wind velocity vector at the rotor, $\mathbf{U}(\mathbf{1}-a)$, and the wind velocity due to rotation of the blade. This rotational component is the vector sum of the blade section velocity, $Q \boldsymbol{r}$, and the induced angular velocity at the blades from angular momentum, $\omega_{r} / 2[5]$.

$$
\Omega r+\left(\frac{\omega}{2}\right) r=\Omega r+\Omega a^{\prime} r=\Omega r\left(1+a^{\prime}\right)
$$

The overall flow situation is shown in Figure (2) and the relationships of the various forces, angles, and a velocity at the blade looking down from the blade tip, are shown in Figure (2).

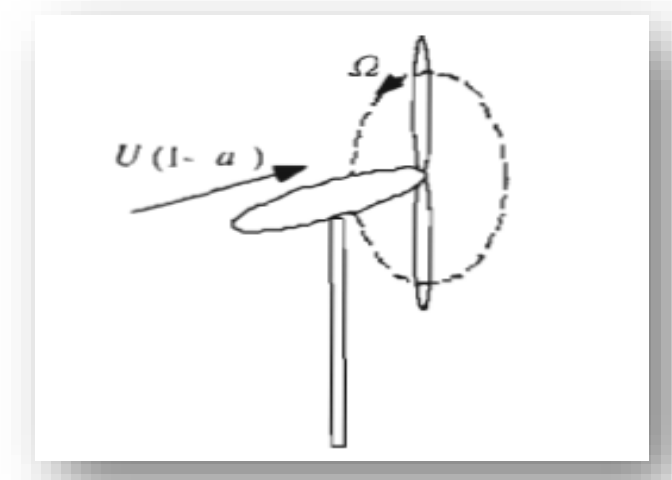

Figure (2) Overall geometry for downwind horizontal axis wind turbine .figure source [4]

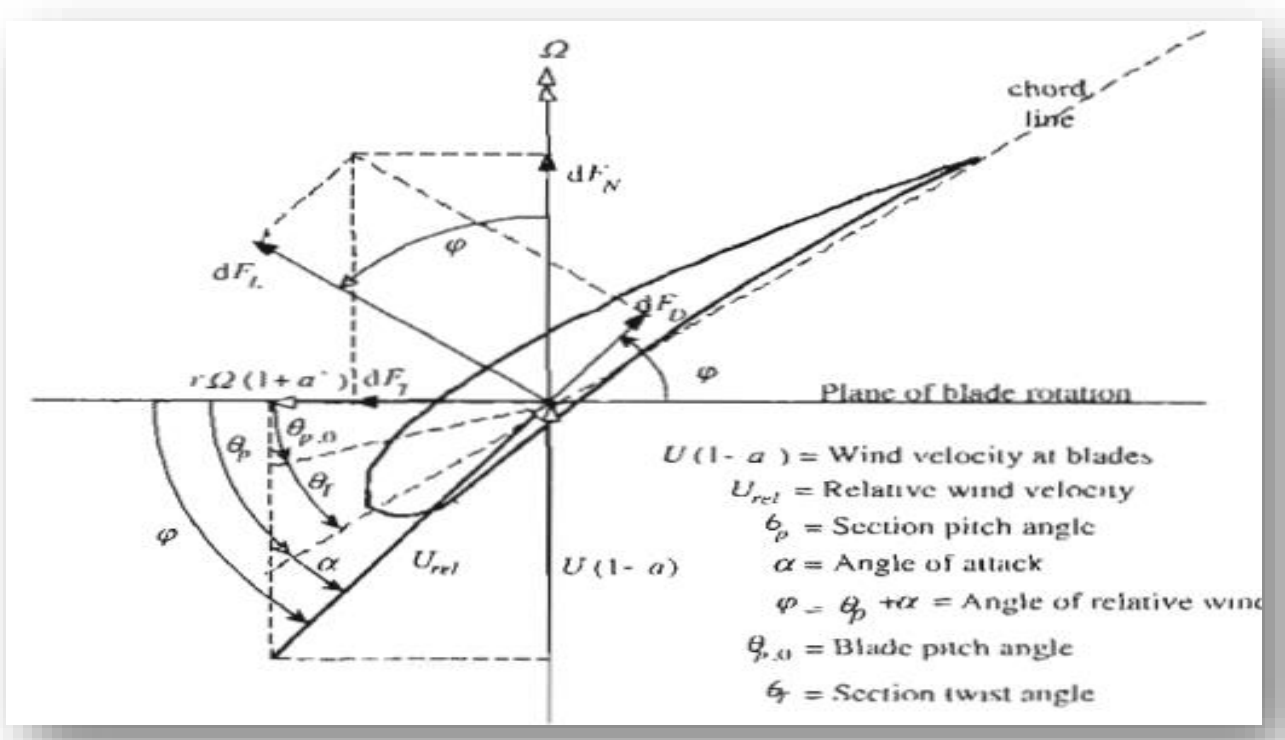

Figure (3) Blade angles for analysis of a horizontal axis wind turbine; fig source [1] 
Journal of University of Babylon for Engineering Sciences, Vol. (26), No. (7): 2018.

For the definition of variables [6]

$$
Q_{T}=Q_{P}-Q_{p o}
$$

Note also that, here, and the blade twist angle, $Q_{T}$ is defined relative to the blade tip (it could be defined otherwise). Therefore:

$$
\varphi=Q_{P}+\alpha
$$

From the figure, it can determine the relationships below: [1]

$$
\begin{aligned}
& \tan \varphi=\frac{U(1-a)}{\Omega r\left(1+a^{\prime}\right)} \frac{1-a}{\left(1+a^{\prime}\right) \lambda_{r}} \\
& U_{r e l}=\frac{u(1-a)}{\sin \varphi} \\
& d F_{L}=c l \frac{1}{2} \rho U_{r e l}^{2} c d r \\
& d F_{D}=c d \frac{1}{2} \rho U_{r e l}^{2} c d r \\
& d F_{N}=d F_{L} \cos \varphi+d F_{D} \sin \varphi \\
& d F_{T}=d F_{L} \sin \varphi+d F_{D} \cos \varphi
\end{aligned}
$$

If the rotor has $\mathrm{B}$ blades, the total normal force on the section at distance $\mathrm{r}$, from the center is

$$
d F_{N}=B \frac{1}{2} \rho U_{\text {real }}^{2}\left(C_{1} \cos \varphi+c d \sin \varphi\right) c d r
$$

The differential torque due to the tangential force operating at a distance $r$, from the center is given by

$$
\begin{aligned}
& d Q=B r d F_{r} \\
& d Q=B \frac{1}{2} \rho U_{r e l}^{2}(C l \sin \varphi-C d \cos \varphi) c r d r
\end{aligned}
$$

Note that the effect of drag is to decrease torque and power, but to increase the thrust loading. 
Journal of University of Babylon for Engineering Sciences, Vol. (26), No. (7): 2018.

\subsection{Blade Shape for Ideal Rotor (without Wake):}

To design tip speed ratio, the required number of blades, B, the diameter of $\mathrm{D}$ or radius of $\mathrm{R}$, and an airfoil with known lift and drag coefficients as need to be chosen. Angle of attack (and, thus, a lift coefficient at which the airfoil operates) is also chosen. This angle of attack should be selected where CLICD, is maximum in order to most closely approximate the assumption that [7]

$\mathrm{Cd}=0$. These choices allow the chord and twist distribution of a blade that would provide Betz limit power production to be determined. With the assumption $a=1 / 3$, thus

$$
d T=\rho U^{2} 4\left(\frac{1}{2}\right)\left(1-\frac{1}{2}\right) \pi r d r=\frac{\rho U^{2} 8}{9 \pi r d r}
$$

And from blade element theory (Equation (12), with $\mathrm{cd}=0$ )

$$
d F_{N}=B \frac{1}{2} \rho U_{r e l}^{2}(C l \cos \varphi) C d r
$$

A third equation, Equation (7), be used to express $U_{r e l}$ in terms of other known variables:

$$
U_{\text {rel }}=\frac{U(1-a)}{\sin \varphi}=\frac{2 U}{3 \sin \varphi}
$$

BEM theory or strip theory refers to the determination of wind turbine blade performance by combining the equations of momentum theory and blade element theory. In this case, equating Equations (15) and (16) and using Equation (17), yields [8]:

$$
\frac{C l B c}{4 \pi r}=\tan \varphi \sin \varphi
$$

A fourth equation, Equation (6), which relates a, a' and q based on geometrical considerations, can be used to solve the blade shape. Equation (6), with $\mathrm{a}^{\prime}=0$ and $a=$ $1 / 3$

$$
\tan \varphi=\frac{2}{3 \lambda_{r}}
$$

Therefore

$$
\frac{C l B c}{4 \pi r}=\left(\frac{2}{3 \lambda_{r}}\right) \sin \varphi
$$

Rearranging, and noting that $\lambda_{r}=\lambda\left(\frac{r}{R}\right)$ one can determined the angle of the relative wind and the chord of the blade for each section of the ideal rotor: 
Journal of University of Babylon for Engineering Sciences, Vol. (26), No. (7): 2018.

$$
\begin{gathered}
\varphi=\tan ^{-1}\left(\frac{2}{3 \lambda_{r}}\right) \\
c=\frac{8 \pi r \sin \varphi}{3 B C l \lambda_{r}}
\end{gathered}
$$

The relative velocity can be expressed as a function of the free stream wind using Equation (7). Thus, Equations (12) and (14) from blade element theory can be expressed as:

$$
\begin{aligned}
& d F_{N}=\sigma^{\prime} \pi \rho \frac{U^{2}(1-a)^{2}}{\sin \varphi^{2}}\left(C_{1} \cos \varphi+c d \sin \varphi\right) r d r \\
& d Q=\sigma^{\prime} \pi \rho \frac{U^{2}(1-a)^{2}}{\sin \varphi^{2}}\left(C_{1} \sin \varphi+c d \cos \varphi\right) r^{2} d r
\end{aligned}
$$

Where $\sigma^{\prime}$ is the local solidity, defined by?

$$
\sigma^{\prime}=B c / 2 \pi r
$$

\subsection{Blade Element Momentum Theory}

In the calculation of induction factors, a and a', accepted practice is to set $C d$ equal to zero. For airfoils with low drag coefficients, this simplification introduces negligible errors. So, when the torque equations from momentum and blade element theory are equated (Equations (2) and (24)), with $C d=0$, one gets [9]:

$$
\frac{a^{\prime}}{1-a}=\frac{\sigma^{\prime} C l}{4 \lambda_{r} \sin \varphi}
$$

By equating the normal force equations from momentum and blade element theory (Equations 1 and 23), one can obtain:

$$
\frac{a^{\prime}}{1-a}=\frac{\sigma^{\prime} C l \cos \varphi}{4 \sin \varphi^{2}}
$$

(which relates a, a', $\varphi$ and $\lambda$, based on geometric considerations) and Equations (26) and (27), the following useful relationships result:

$$
C l=4 \sin \varphi \frac{\left(\cos \varphi-\lambda_{r} \sin \varphi\right)}{\sigma^{\prime}\left(\sin \varphi-\lambda_{r} \cos \varphi\right)}
$$

Other useful relationships that may be derived include:

$$
a^{\prime}=\frac{1}{\left\{\left(\frac{\cos \varphi}{\sigma^{\prime} C l}\right)--1\right\}}
$$


Journal of University of Babylon for Engineering Sciences, Vol. (26), No. (7): 2018.

\subsection{Calculation of Power Coefficient}

Has been obtained from each section, where the overall rotor power coefficient may be calculated by the following equation [10]

$$
C p=\left(8 / \lambda^{2}\right) \int_{\lambda_{h}}^{\lambda} \lambda_{r}{ }^{3} a^{\prime}(1-a)\left[1-\left(\frac{C d}{C l}\right) \cot \varphi\right] d \lambda_{r}
$$

Using the expression for the differential torque from Equation (24) and the definition of the local tip speed ratio:

$$
C p=\left(2 / \lambda^{2}\right) \int_{\lambda_{h}}^{\lambda} \sigma^{\prime} C l(1-a)^{2}(1-\sin \varphi)\left[1-\left(\frac{C d}{C l}\right) \cot \varphi\right] \lambda_{r}{ }^{2} d \lambda_{r}
$$

Note that when $C d=0$, this equation for $\mathrm{Cp}$ is the same as the one derived from momentum theory, including wake rotation, we get:

Optimized From the analysis of wind turbine design, it's necessary to specify some parameters which have a major effect on power coefficient and keep some other fixed through the analysis as shown below.

\begin{tabular}{|c|c|}
\hline \multicolumn{2}{|c|}{ Parameters } \\
\hline Fixed & Variables \\
\hline Radius of Rotor $=1.07 \mathrm{~m}$ & Blade Cross Section \\
\hline Number of Blade $=3$ & Blade Chord \\
\hline Hub Diameter $=0.19 \mathrm{~m}$ & Pitch Angle \\
\hline Tip seep Ratio $=7$ & Angle of Attack \\
\hline
\end{tabular}

\subsection{Blade Cross Section}

The main parameters for choosing the wind turbine blade airfoil are:

1. Thickness to chord ratio $(\mathrm{t} / \mathrm{c})$.

2. Lift to drag ratio $(\mathrm{cl} / \mathrm{cd})$.

3. The intensity of roughness.

4. Low Noise.

5. Stall condition.

To compare the behavior of the unsymmetrical and supercritical blade cross section for high-performance power generation.

There are two fundamental assumptions necessary to extend the analysis:

1. The flow in each stream tube is independent of that the other stream tube.

2. The forces acting on each blade element are the same as those on the airfoil of the same section, the angle of attack, and effective velocity. 
Journal of University of Babylon for Engineering Sciences, Vol. (26), No. (7): 2018.

The two-airfoil section selected which has been used previously in many wind turbines as shown below.

\begin{tabular}{|c|c|c|c|c|c|}
\hline Airfoil & $\mathrm{t} / \mathrm{c}$ & Max L/D & $\begin{array}{c}\text { Stall } \\
\text { angle }\end{array}$ & Noise & Description \\
\hline NACA & $\begin{array}{c}12 \% \text { at } \\
4412\end{array}$ & $\begin{array}{c}129.37 \text { at } \\
\alpha=5.25^{\circ}\end{array}$ & $15 \mathrm{deg}$ & less & Unsymmetrica \\
& $\alpha=2 \%$ at & 135.9 at & $13.5 \mathrm{deg}$ & more & Super Critical \\
\hline Eppler 417 & $\begin{array}{c}14.2 \% 5^{\circ} \\
38.3 \% \text { chord }\end{array}$ & & & \\
\hline
\end{tabular}

Airfoils geometry is shown in the figure (4) and Figure (5) and their Characteristic Figure (6) to Figure (7)

\subsection{Lift to Drag Ratio}

The fox point was to select highest L/D zone for an airfoil with their related angle of attack which is obviously different from airfoil to airfoil depend on the lift to drag behavior. These selected angles were distributed along the wind turbine blade radius to obtain approximate equal lift/drag ratio for each section to optimize the power coefficient. Best airfoil gives high lift/drag ratio at a low angle of attack behind the stalling angle which gives the benefit that any change in wind angle the airfoil will be still working.

NACA 4412 gives a lift to drag zone with $(133.8 \mathrm{~L} / \mathrm{D})$ at $(6 \mathrm{deg})$ of the angle of attack and $(0.107 \mathrm{~m})$ blade length, $(125.13 \mathrm{~L} / \mathrm{D})$ at $(3.75 \mathrm{deg})$ of the angle of attack and (1.07 m) blade length (Fig. 6).

Eppler 417 gives a lift to drag zone with (148.60 L/D) at (2.25 deg) angle of attack and $(0.107 \mathrm{~m})$ blade length, $(91.545 \mathrm{~L} / \mathrm{D})$ at $(0 \mathrm{deg})$ angle of attack and $(1.07 \mathrm{~m})$ blade length (Figure (6)).

From Figure (7) to Figure (12) it appears that the best lift, drag and lifts to drag ratio selected to optimize the power coefficient for NACA 4412 and Eppler 417 respectively.

Equal lift to drag ratio along the wind turbine blade radius reduces the tip loss factor and the blade behavior becomes less noisy for that NACA 4412 perform better than EPPLER 417 in the noise field.

\subsection{Twist angle}

The twist angle is the angle between the plane of rotation of the blade and the elements chord line, sometimes is termed as pitch angle. The Twist angle depends on tip speed ratio and airfoil angle of attack. Pitch angle usually high at the root of the blade and at the tip of the blade to decrease tip loss factor and reduce the noise. From the calculations it is found that NACA 4412 required $(0.158 \mathrm{~m})$ chord at $(6 \mathrm{deg})$ angle of attack at the root and $(3.75 \mathrm{deg})$ and $(0.045 \mathrm{~m})$ at the tip, Eppler 417 required $(0.22047$ $\mathrm{m})$ at $(2.25 \mathrm{deg})$ angle of attack at the root and $(0 \mathrm{deg}),(0.796 \mathrm{~m})$ chord at tip at the same radius section. That mean NACA 4412 thinner than Eppler 417 and less cost but Eppler 
Journal of University of Babylon for Engineering Sciences, Vol. (26), No. (7): 2018.

417 behavior better than NACA 4412in facing the wind stream because haveing a less setting angle, as shown in Figures (13) and (14).

\subsection{Chord length}

The most powerful parameter in the wind turbine blade for aerodynamic and structural design, high lift root airfoil to minimize inboard solidity and enhance starting torque. Obviously, the setting angle at the blade root be high and then die at the tip to decrease the tip loss factor and air noise. From the calculations, it is found that the taper ratio equal to (0.2), also found a good starting design point of view. The comparison of the two airfoils chord length distributed along blade radius has been presented in figure (7).

\subsection{Optimization}

From the analysis, it is found that two main parameters that improve the aerodynamic principle behavior of wind turbine blade to capture the wind energy more effectively were the twist angle and chord length, so it must optimize this two parameters using the lift to drag method for twist angle, Schmitz, and Betz for chord length.

According to Betz method, the blade length should become increase thick as it approaches the hub, where the Schmitz method show that the blade length starts thin closest to the hub, reaches a maximum about $13 \%$ of the blade length and begins to decrease again. The difference in pitch angle is greatest at the hub of the turbine blade a difference of about 20 degrees at $5 \%$ of the blade length. The difference decreases after about $50 \%$ of the blade length when the two lines are within a degree of one another since the hub of the turbine with likely consumes the first $10 \%$ of blade length. It appears that is a small variation in results regardless of the method.

The optimization methods have been applied to the two airfoils NACA 4412 and Eppler 417 airfoils and with the following cases:

1- Nontwist optimization, Schmitz chord optimization chord.

2- Nontwist optimization, Betz chord optimization method.

3- Lift/drag twist optimization method, non-chord optimization.

4- Lift/drag twist optimization method, Schmitz chord optimization.

5- Lift/drag twist optimization method, Betz chord optimization.

The effect of these optimization methods on the two airfoils performance and the resultant power coefficient and thrust coefficients for the non-optimization case and overall above optimization methods has been presented in figures from (15) to (27), also tables from (7) to (12). 
Journal of University of Babylon for Engineering Sciences, Vol. (26), No. (7): 2018.

\section{Conclusions:}

It can be concluded from the previous analysis, which can behave the further wind turbine design.

1. The main factor has power affects on wind turbine power airfoil section and its characteristic are (Lift, Drag, $L / D$, angle of attack, blade chord length and blade pitch angle).

2. EPPLER 417 airfoil behavior better in turbulent and has a lower angle of attack than NACA4412.

3. EPPLER 417 is more costly than NACA4412 because it's had bigger geometry.

4. Pitch angle highly at the root $\left(43^{\circ}\right)$ and approximately zero at the tip in order to integrate better angle of attack distribution.

5. Equal Lift to drag distribution on blade length decreases the tip loss and higher power coefficient.

6. EPPLER 417 airfoil has low starting speed a NACA4412 du to optimum lift value at a low angle of attack.

7. Thicker root chord and thinner root chord increase solidity, decrease tip low ration and decrease tip wake generation (noise).

Table (1) Calculated Aerodynamic Data for Eppler-417

\begin{tabular}{|l|l|l|l|l|l|l|l|l|}
\hline NO & $\mathrm{I}$ & ALFA & $\mathrm{i}$ & Chord & $\mathrm{r}$ & $\mathrm{CL}(\mathrm{I})$ & $\mathrm{CD}(\mathrm{I})$ & $\mathrm{L} / \mathrm{D}$ \\
\hline 1 & 36.67198 & 30.67198 & 6 & 0.15788 & 0.107 & 1.1238 & 0.0084 & 133.7857 \\
\hline 2 & 23.69178 & 17.94178 & 5.75 & 0.13715 & 0.214 & 1.1017 & 0.00821 & 134.1619 \\
\hline 3 & 16.97556 & 11.47556 & 5.5 & 0.10861 & 0.321 & 1.07882 & 0.00804 & 134.1196 \\
\hline 4 & 13.10254 & 7.85254 & 5.25 & 0.08848 & 0.428 & 1.05499 & 0.00789 & 133.6881 \\
\hline 5 & 10.63026 & 5.63026 & 5 & 0.07468 & 0.535 & 1.03 & 0.00775 & 132.9032 \\
\hline 6 & 8.92833 & 4.17833 & 4.75 & 0.06493 & 0.642 & 1.00367 & 0.00761 & 131.8051 \\
\hline 7 & 7.68974 & 3.18974 & 4.5 & 0.05783 & 0.749 & 0.97582 & 0.00748 & 130.4361 \\
\hline 8 & 6.74978 & 2.49978 & 4.25 & 0.05253 & 0.856 & 0.94626 & 0.00734 & 128.8391 \\
\hline 9 & 6.01288 & 2.01288 & 4 & 0.04852 & 0.963 & 0.9148 & 0.0072 & 127.0555 \\
\hline 10 & 5.42006 & 1.67006 & 3.75 & 0.04548 & 1.07 & 0.88125 & 0.00704 & 125.1248 \\
\hline
\end{tabular}


Journal of University of Babylon for Engineering Sciences, Vol. (26), No. (7): 2018.

Table (2) Calculated Power Data for Epler-417

\begin{tabular}{|c|c|c|c|c|}
\hline ALO & CF & CM & CP & TORQUE \\
\hline 1 & 0.2208 & -0.0118 & -0.0118 & -0.0213 \\
\hline 2 & 0.1755 & 0.0101 & 0.0202 & 0.0139 \\
\hline 3 & 0.2886 & 0.0482 & 0.1446 & 0.0596 \\
\hline 4 & 0.5192 & 0.083 & 0.332 & 0.0973 \\
\hline 5 & 0.6896 & 0.0869 & 0.4347 & 0.0987 \\
\hline 6 & 0.7949 & 0.0801 & 0.4809 & 0.0891 \\
\hline 7 & 0.8727 & 0.0708 & 0.4954 & 0.0774 \\
\hline 8 & 0.9042 & 0.061 & 0.4878 & 0.066 \\
\hline 9 & 0.9008 & 0.0527 & 0.4744 & 0.0565 \\
\hline 10 & 0.8771 & 0.0461 & 0.4611 & 0.0491 \\
\hline 11 & 0.8403 & 0.0407 & 0.4476 & 0.0431 \\
\hline 12 & 0.7152 & 0.0349 & 0.4193 & 0.0368 \\
\hline 13 & 0.665 & 0.0308 & 0.4005 & 0.0323 \\
\hline 14 & 0.6031 & 0.0266 & 0.3719 & 0.0278 \\
\hline 15 & 0.5285 & 0.0221 & 0.3311 & 0.023 \\
\hline 16 & 0.4439 & 0.0174 & 0.2783 & 0.0181 \\
\hline 17 & 0.3498 & 0.0126 & 0.2137 & 0.013 \\
\hline 18 & 0.2228 & 0.0064 & 0.1145 & 0.0066 \\
\hline 19 & 0.0947 & 0.0007 & 0.0139 & 0.0008 \\
\hline 20 & 0.0926 & 0.001 & 0.0207 & 0.0011 \\
\hline
\end{tabular}

Table (3) Calculated Aerodynamic Data for NACA 4412

\begin{tabular}{|c|c|c|c|c|c|c|c|c|c|c|}
\hline NO & I & ALFA & i & Chord & r & X & Y & CD(I) & CL(I) & L/D \\
\hline 1 & 36.67198 & 34.42198 & 2.25 & 0.22047 & 0.107 & 0.18186 & 0.12463 & 0.00542 & 0.80477 & 148.6024 \\
\hline 2 & 23.69178 & 21.69178 & 2 & 0.19265 & 0.214 & 0.17901 & 0.07121 & 0.0055 & 0.7843 & 142.6 \\
\hline 3 & 16.97556 & 15.22556 & 1.75 & 0.15405 & 0.321 & 0.14865 & 0.04046 & 0.00561 & 0.76057 & 135.59 \\
\hline 4 & 13.10254 & 11.60254 & 1.5 & 0.12725 & 0.428 & 0.12465 & 0.02559 & 0.00573 & 0.7336 & 128.1397 \\
\hline 5 & 10.63026 & 9.38026 & 1.25 & 0.10936 & 0.535 & 0.1079 & 0.01782 & 0.00583 & 0.70337 & 120.6863 \\
\hline 6 & 8.92833 & 7.92833 & 1 & 0.09728 & 0.642 & 0.09635 & 0.01342 & 0.0059 & 0.6699 & 113.5424 \\
\hline 7 & 7.68974 & 6.93974 & 0.75 & 0.08912 & 0.749 & 0.08847 & 0.01077 & 0.00592 & 0.63317 & 106.9214 \\
\hline 8 & 6.74978 & 6.24978 & 0.5 & 0.08379 & 0.856 & 0.08329 & 0.00912 & 0.00587 & 0.5932 & 100.9702 \\
\hline 9 & 6.01288 & 5.76288 & 0.25 & 0.0807 & 0.963 & 0.0803 & 0.0081 & 0.00574 & 0.54997 & 95.80402 \\
\hline 10 & 5.42006 & 5.42006 & 0 & 0.0796 & 1.07 & 0.07924 & 0.00752 & 0.0055 & 0.5035 & 91.54546 \\
\hline
\end{tabular}


Journal of University of Babylon for Engineering Sciences, Vol. (26), No. (7): 2018.

Table (4) Calculated Power Data for NACA 4412

\begin{tabular}{|c|c|c|c|c|}
\hline ALO & CF & CM & CP & TORQE \\
\hline 1 & 0.2667 & -0.0119 & -0.0119 & -0.0216 \\
\hline 2 & 0.2536 & 0.0149 & 0.0297 & 0.0204 \\
\hline 3 & 0.3634 & 0.0562 & 0.1685 & 0.0695 \\
\hline 4 & 0.3367 & 0.0349 & 0.28 & 0.0409 \\
\hline 5 & 0.5616 & 0.0633 & 0.4166 & 0.0719 \\
\hline 6 & 0.7785 & 0.0756 & 0.4539 & 0.0841 \\
\hline 7 & 0.852 & 0.0685 & 0.4797 & 0.075 \\
\hline 8 & 0.8384 & 0.0598 & 0.4784 & 0.0647 \\
\hline 9 & 0.7904 & 0.0523 & 0.4709 & 0.0561 \\
\hline 10 & 0.7168 & 0.0456 & 0.4562 & 0.0486 \\
\hline 11 & 0.6245 & 0.0392 & 0.4309 & 0.0415 \\
\hline 12 & 0.5092 & 0.0328 & 0.3937 & 0.0346 \\
\hline 13 & 0.3805 & 0.0265 & 0.3443 & 0.0278 \\
\hline 14 & 0.2225 & 0.0195 & 0.2729 & 0.0204 \\
\hline 15 & 0.0494 & 0.0128 & 0.1925 & 0.0134 \\
\hline 16 & -0.111 & 0.0066 & 0.1056 & 0.0069 \\
\hline 17 & -0.2903 & -0.0038 & -0.0646 & -0.0039 \\
\hline 18 & -0.2847 & -0.0047 & -0.0842 & -0.0048 \\
\hline 19 & -0.208 & -0.0028 & -0.0523 & -0.0028 \\
\hline 20 & -0.3216 & -0.0092 & -0.1848 & -0.0095 \\
\hline
\end{tabular}

Table (5) Blade with Twist and Chord optimization only/Shmiz

\begin{tabular}{|c|c|c|c|c|c|c|}
\hline \multicolumn{5}{|c|}{ NACA 4412 } & \multicolumn{3}{c|}{ Eppler 417 } \\
\hline $\begin{array}{c}\text { Sec } \\
\text { No }\end{array}$ & Radius & Chord & Twist & Radius & Chord & Twist \\
\hline $\mathbf{1}$ & 0.0 & 0.166919 & 43.39 & 0.0 & 0.287904 & 48.4291 \\
\hline $\mathbf{2}$ & 0.104 & 0.156825 & 23.14 & 0.104 & 0.269966 & 28.0198 \\
\hline $\mathbf{3}$ & 0.17 & 0.136238 & 16.72 & 0.17 & 0.234985 & 21.7185 \\
\hline $\mathbf{4}$ & 0.27 & 0.109743 & 10.91 & 0.27 & 0.189287 & 15.9082 \\
\hline $\mathbf{5}$ & 0.37 & 0.0904607 & 7.42 & 0.37 & 0.158887 & 12.7042 \\
\hline $\mathbf{6}$ & 0.47 & 0.0764537 & 5.11 & 0.47 & 0.131868 & 10.1101 \\
\hline $\mathbf{7}$ & 0.57 & 0.065998 & 3.47 & 0.57 & 0.113837 & 8.4723 \\
\hline $\mathbf{8}$ & 0.67 & 0.0579645 & 2.25 & 0.67 & 0.00999 & 7.2524 \\
\hline $\mathbf{9}$ & 0.77 & 0.0516232 & 1.31 & 0.77 & 0.0890403 & 6.30934 \\
\hline $\mathbf{1 0}$ & 0.87 & 0.0465043 & 0.56 & 0.87 & 0.0802111 & 5.55887 \\
\hline $\mathbf{1 1}$ & 0.97 & 0.0422921 & -0.05 & 0.97 & 0.0729559 & 4.94766 \\
\hline $\mathbf{1 2}$ & 1.07 & 0.038769 & -0.56 & 1.07 & 0.0668693 & 4.4037 \\
\hline
\end{tabular}


Journal of University of Babylon for Engineering Sciences, Vol. (26), No. (7): 2018.

Table ( 6 ) Blade with Twist and Chord optimization only/Bitz

\begin{tabular}{|c|c|c|c|c|c|c|}
\hline \multicolumn{4}{|c|}{ NACA 4412} & \multicolumn{3}{|c|}{ Eppler 417} \\
\hline $\begin{array}{c}\text { Sec } \\
\text { No }\end{array}$ & Radius & Chord & Twist & Radius & Chord & Twist \\
\hline 1 & 0.0 & 0.25 & 43.39 & 0.0 & 0.2 & 48.4291 \\
\hline 2 & 0.104 & 0.201076 & 23.14 & 0.104 & 0.345 & 28.0198 \\
\hline 3 & 0.17 & 0.159467 & 16.72 & 0.17 & 0.275051 & 21.7185 \\
\hline 4 & 0.27 & 0.12009 & 10.91 & 0.27 & 0.207133 & 15.9082 \\
\hline 5 & 0.37 & 0.095833 & 7.42 & 0.37 & 0.168725 & 12.7042 \\
\hline 6 & 0.47 & 0.0795659 & 5.11 & 0.47 & 0.137236 & 10.1101 \\
\hline 7 & 0.57 & 0.0679529 & 3.47 & 0.57 & 0.117206 & 8.4723 \\
\hline 8 & 0.67 & 0.0592666 & 2.25 & 0.67 & 0.102224 & 7.2524 \\
\hline 9 & 0.77 & 0.052533 & 1.31 & 0.77 & 0.0906096 & 6.30934 \\
\hline 10 & 0.87 & 0.0471643 & 0.56 & 0.87 & 0.0813495 & 5.55887 \\
\hline 11 & 0.97 & 0.0427857 & -0.05 & 0.97 & 0.0737972 & 4.94766 \\
\hline 12 & 1.07 & 0.0391476 & -0.56 & 1.07 & 0.0675223 & 4.4037 \\
\hline
\end{tabular}

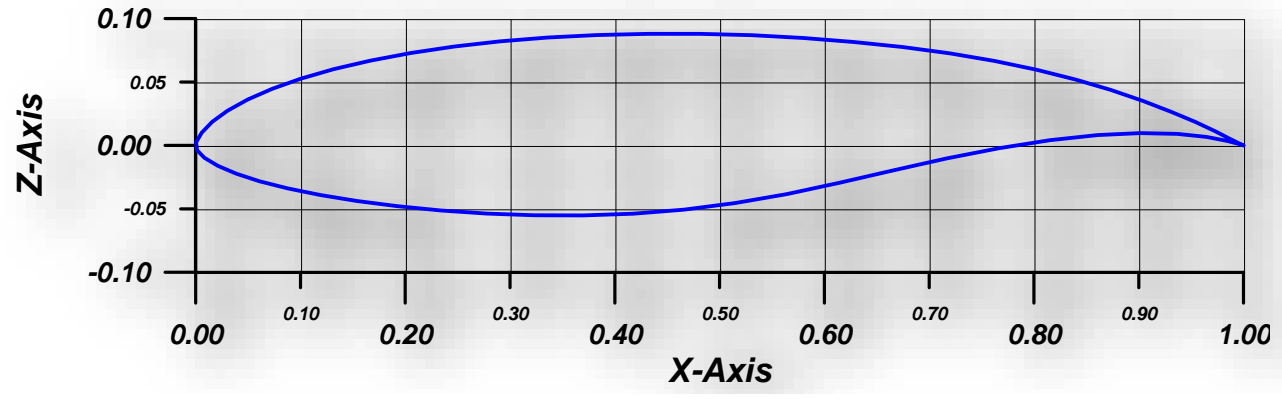

Figure (4) EPPLER 417 airfoil

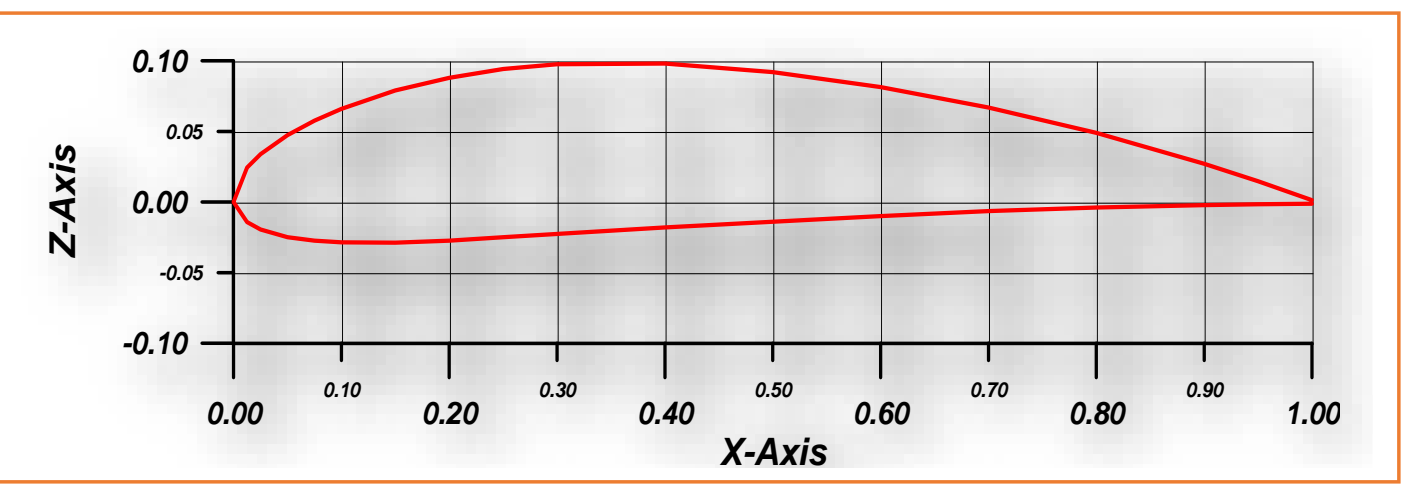

Figure (5) NACA 4412 airfoil 
Journal of University of Babylon for Engineering Sciences, Vol. (26), No. (7): 2018.

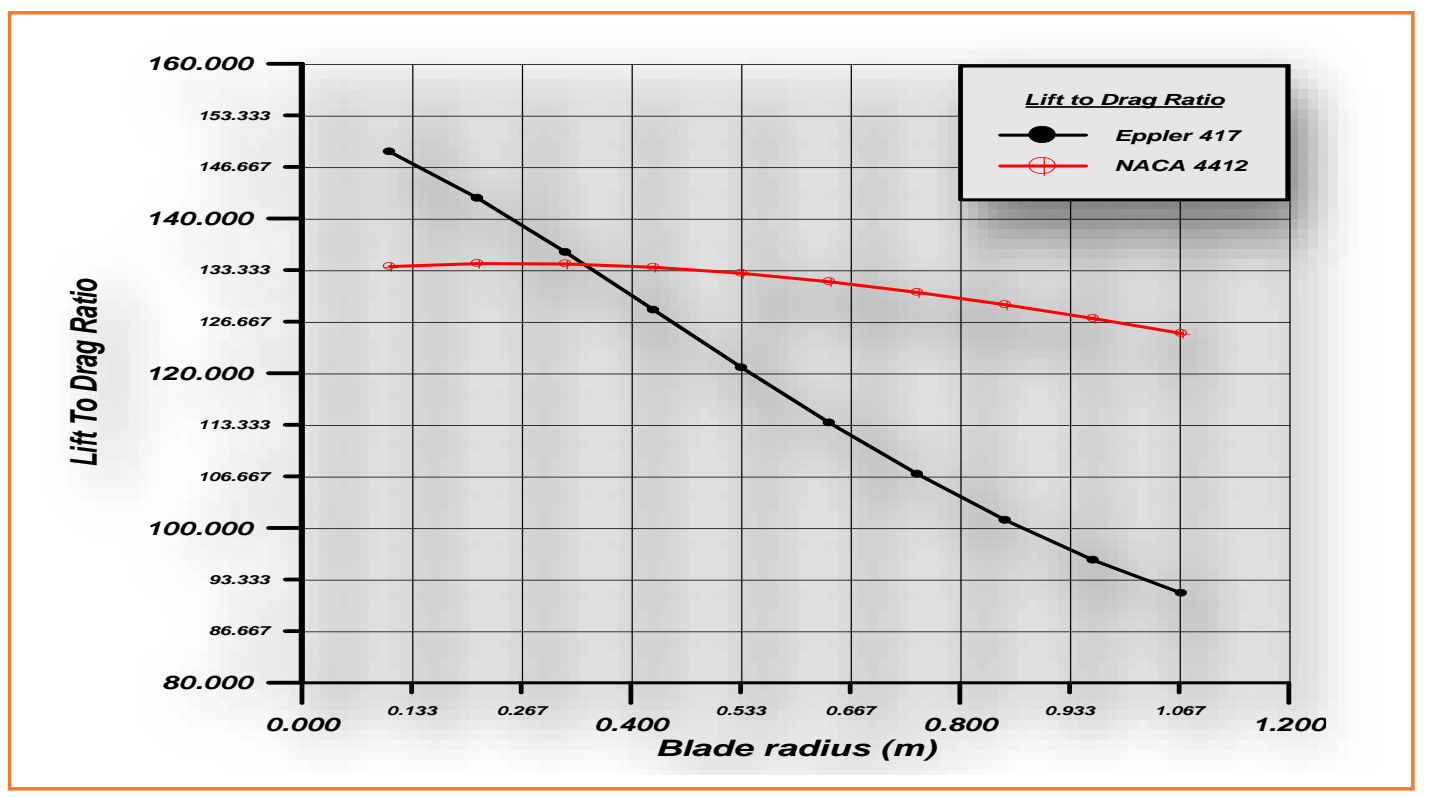

Figure (6) Lift to Drag Comparison

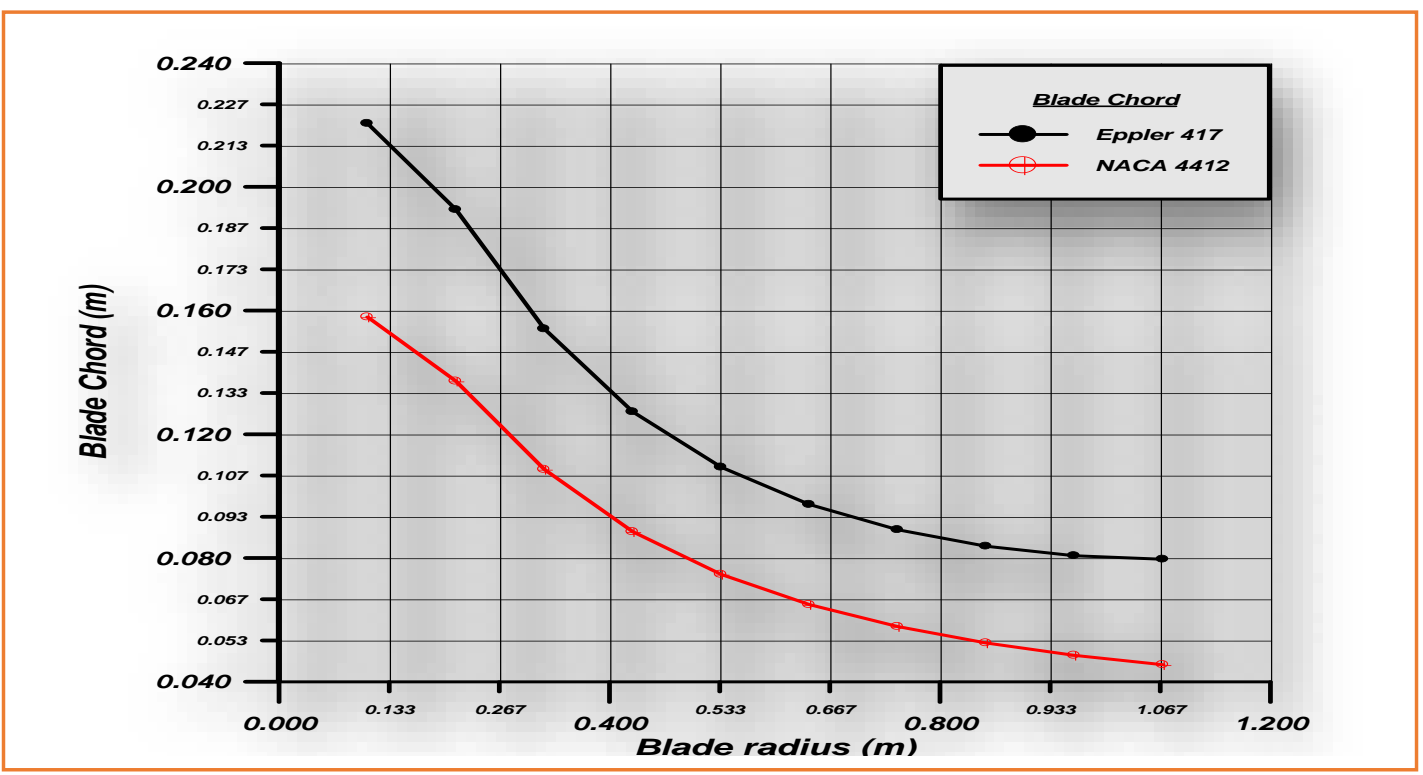

Figure (7) Relation between Blade Chord and Blade Radius 
Journal of University of Babylon for Engineering Sciences, Vol. (26), No. (7): 2018.

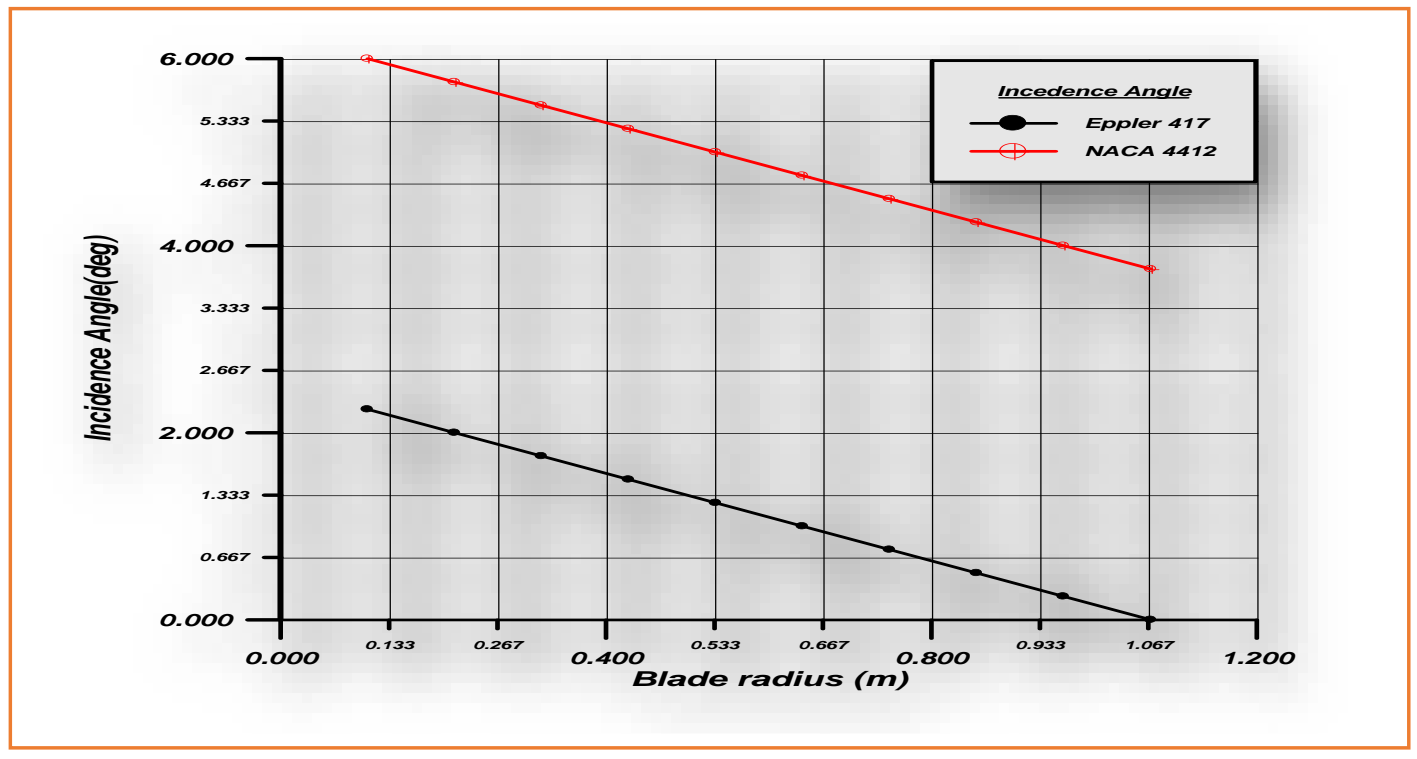

Figure (8) Relation between incidence Angle and Blade Radius

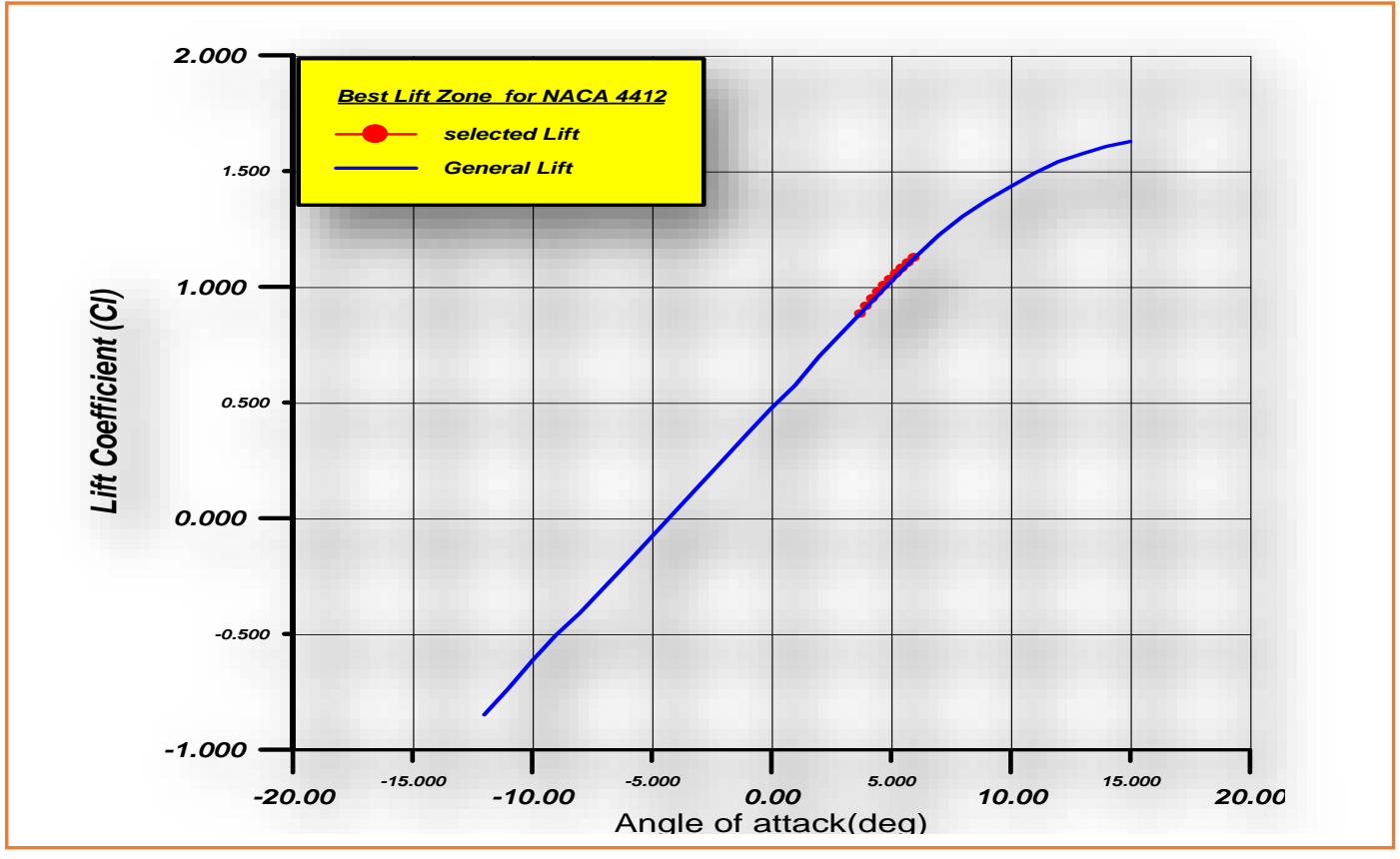

Figure (9) Best Lift Zone for NACA 4412 
Journal of University of Babylon for Engineering Sciences, Vol. (26), No. (7): 2018.

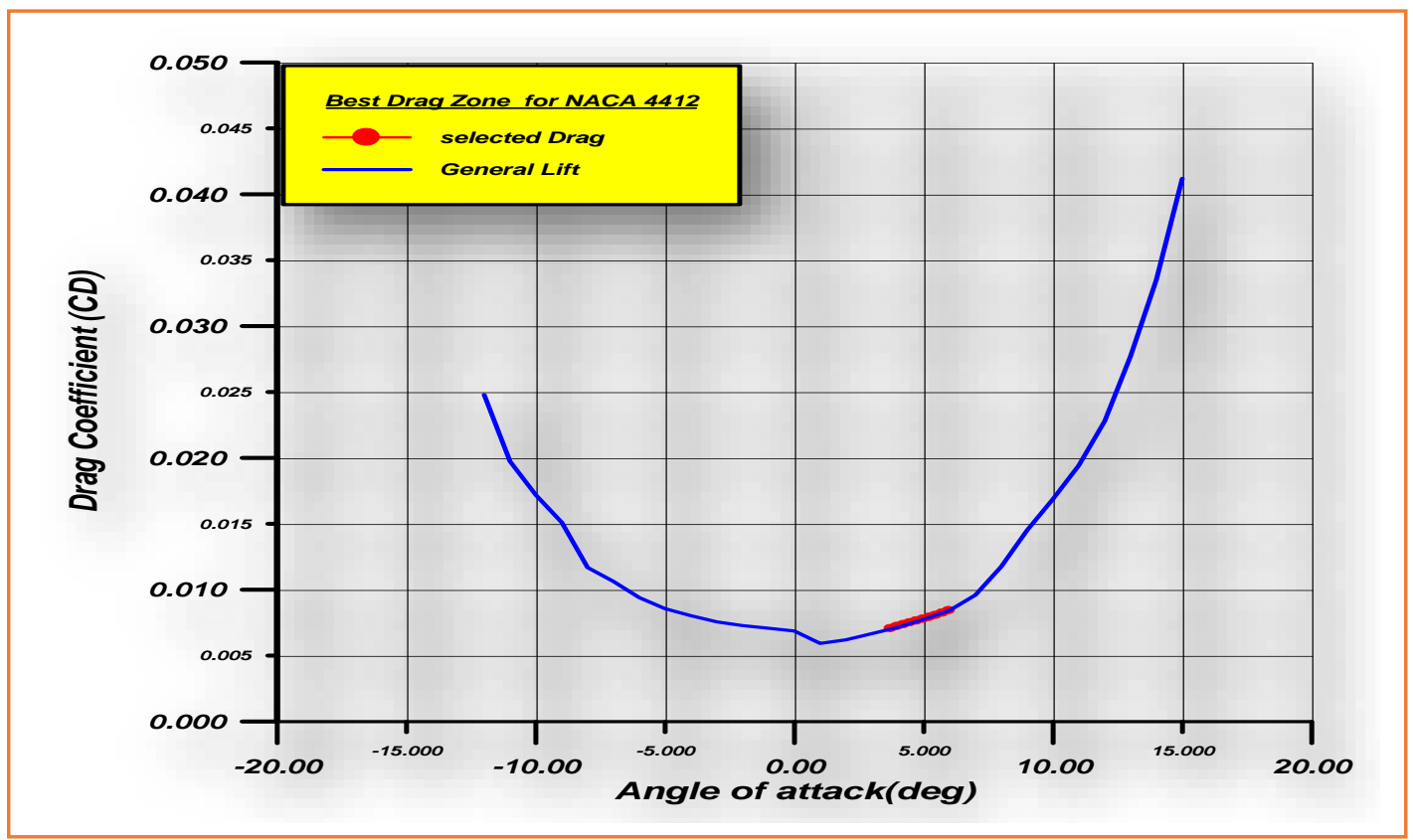

Figure (10) Best Drag Zone for NACA 4412

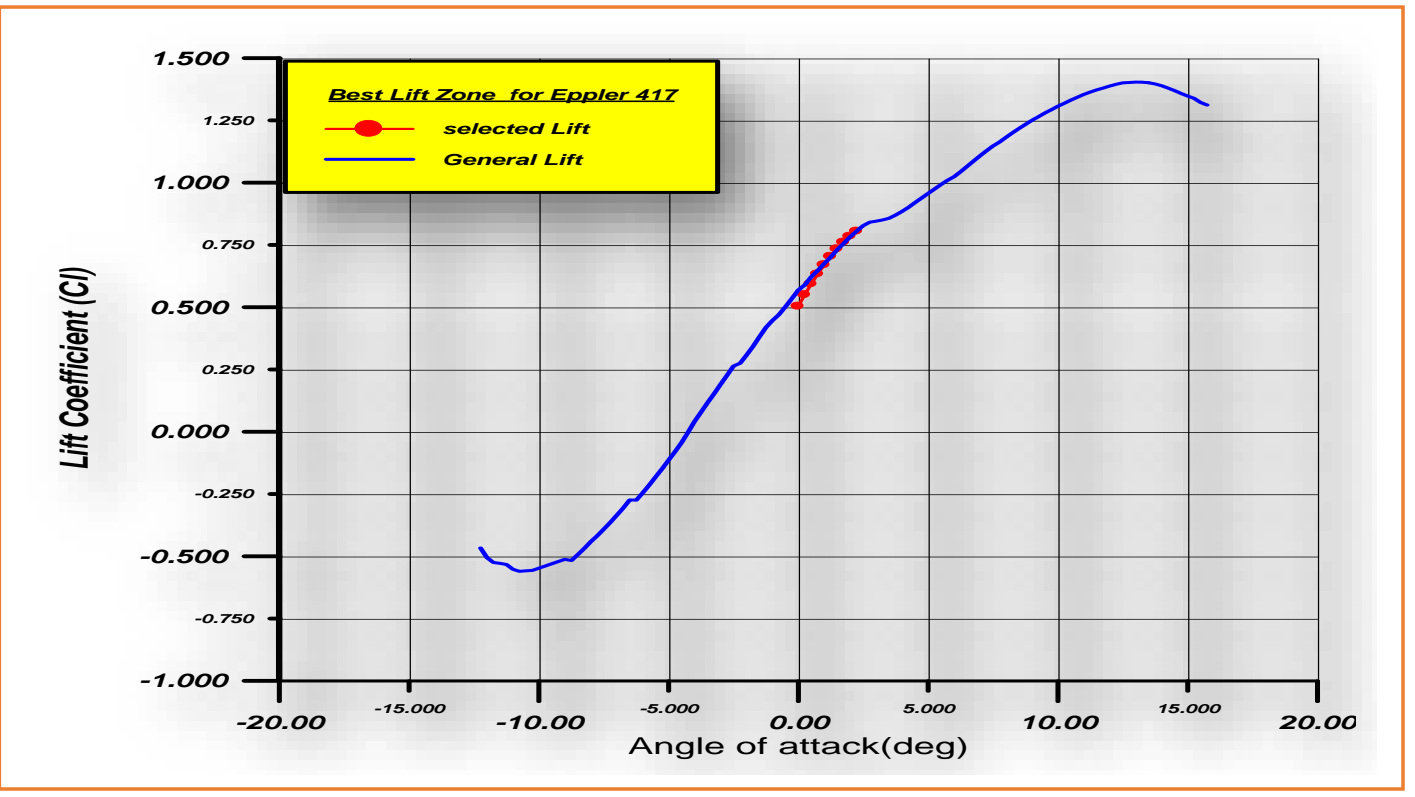

Figure (11) Best Drag Zone for NACA 4412 
Journal of University of Babylon for Engineering Sciences, Vol. (26), No. (7): 2018.

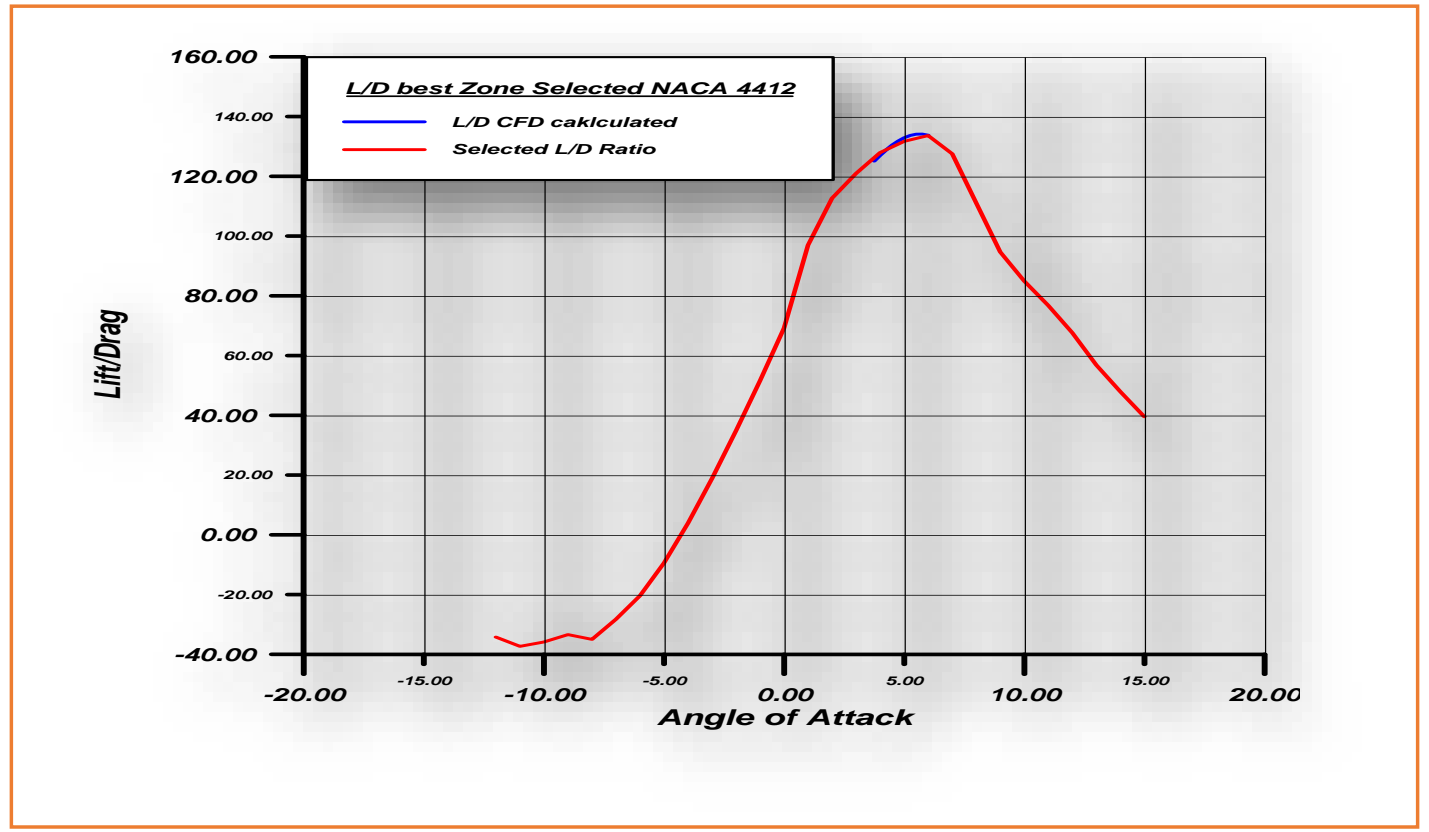

Figure (12) Best Drag Zone for Eppler 417

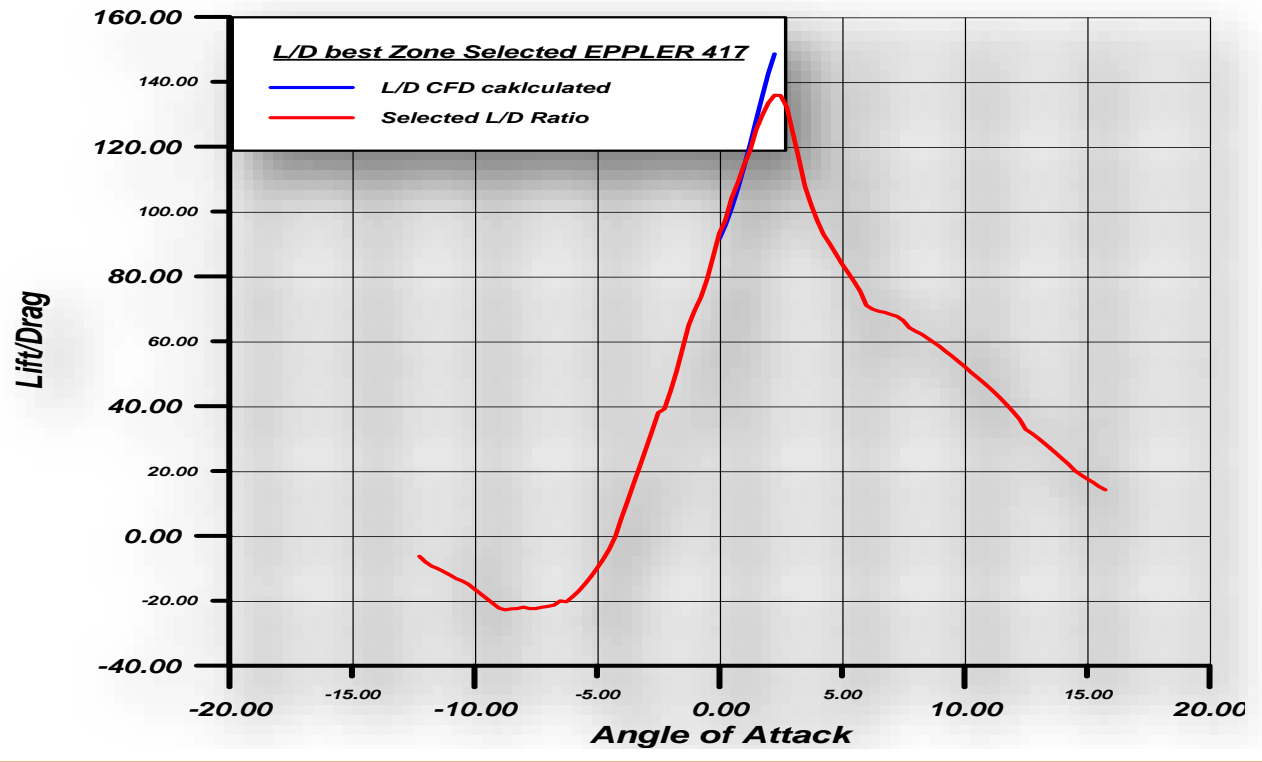

Figure (13) Best Lift/Drag Zone for NACA 4412 
Journal of University of Babylon for Engineering Sciences, Vol. (26), No. (7): 2018.

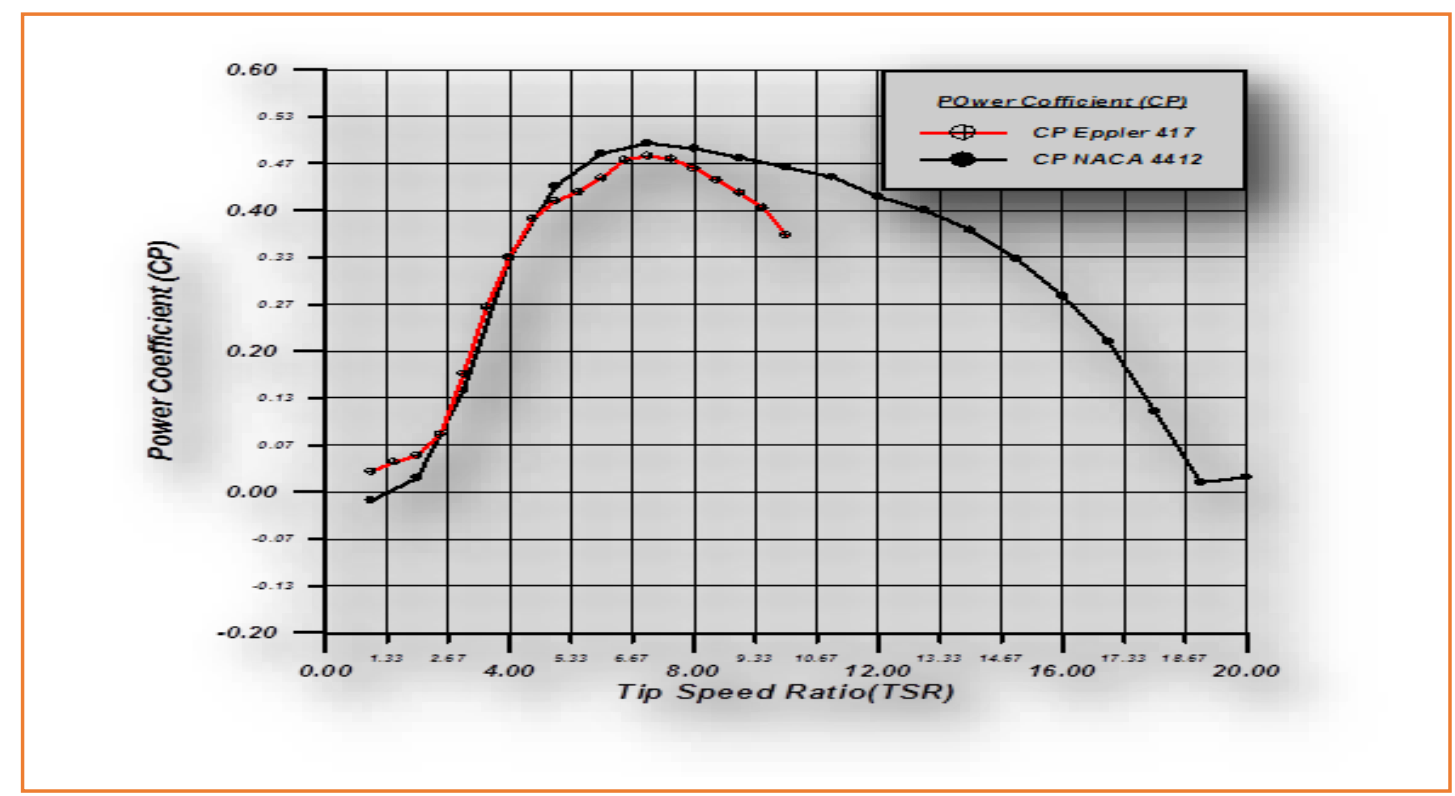

Figure (14) Best lift/Drag Zone for Eppler 417

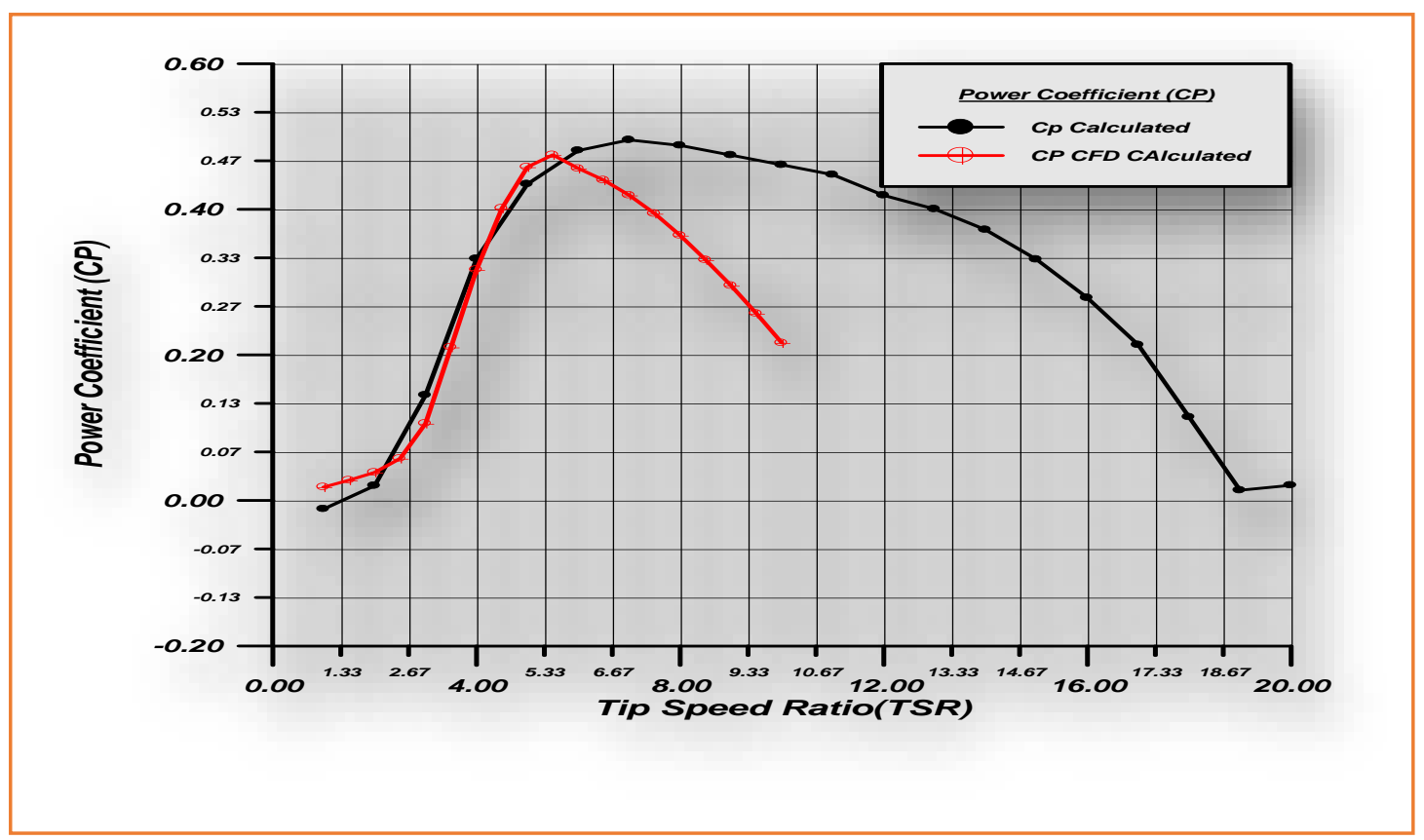

Figure (15) coefficient of Power Comparison 
Journal of University of Babylon for Engineering Sciences, Vol. (26), No. (7): 2018.

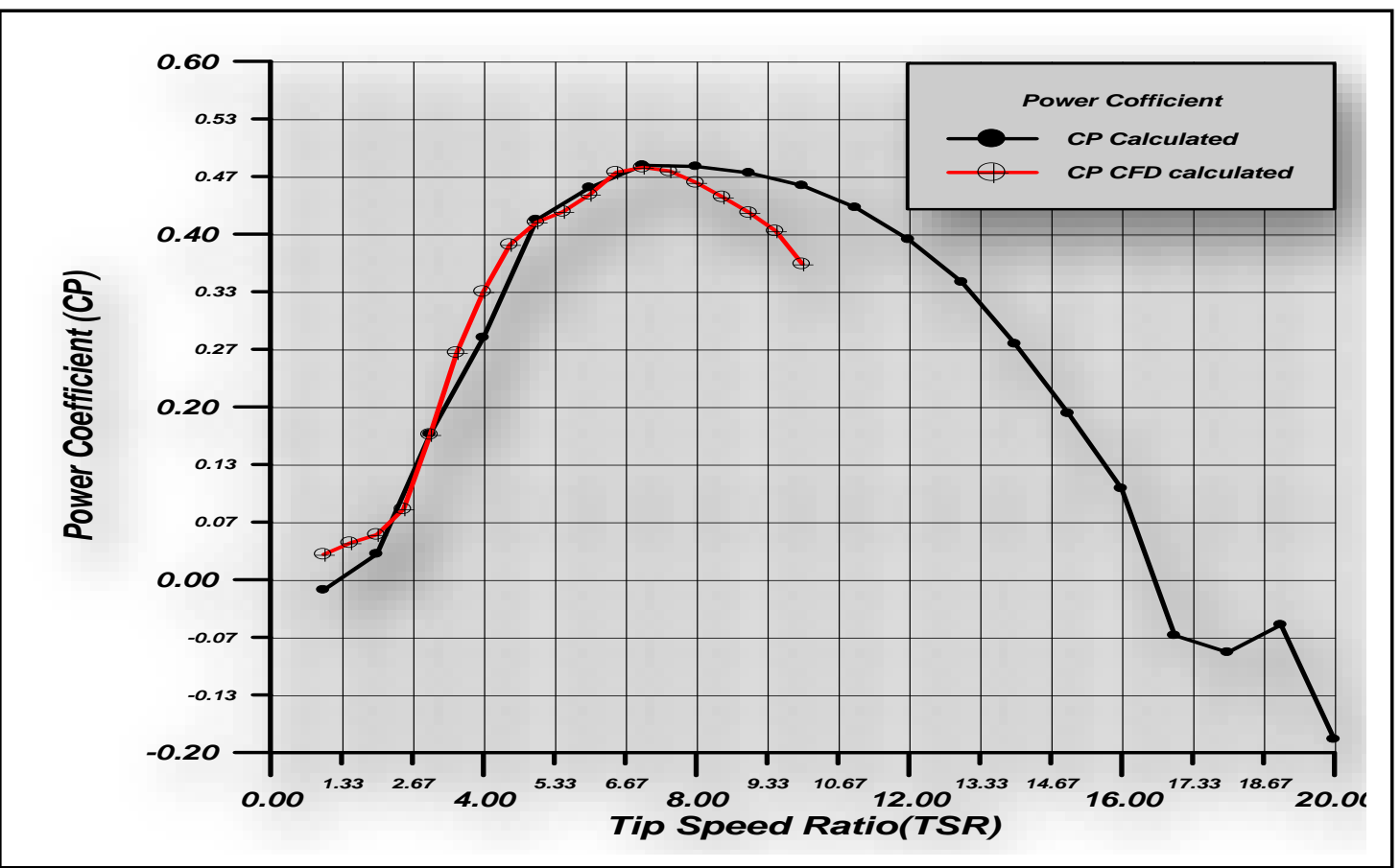

Figure (16) Lift to Drag Comparison Calculated CP and CFD calculation

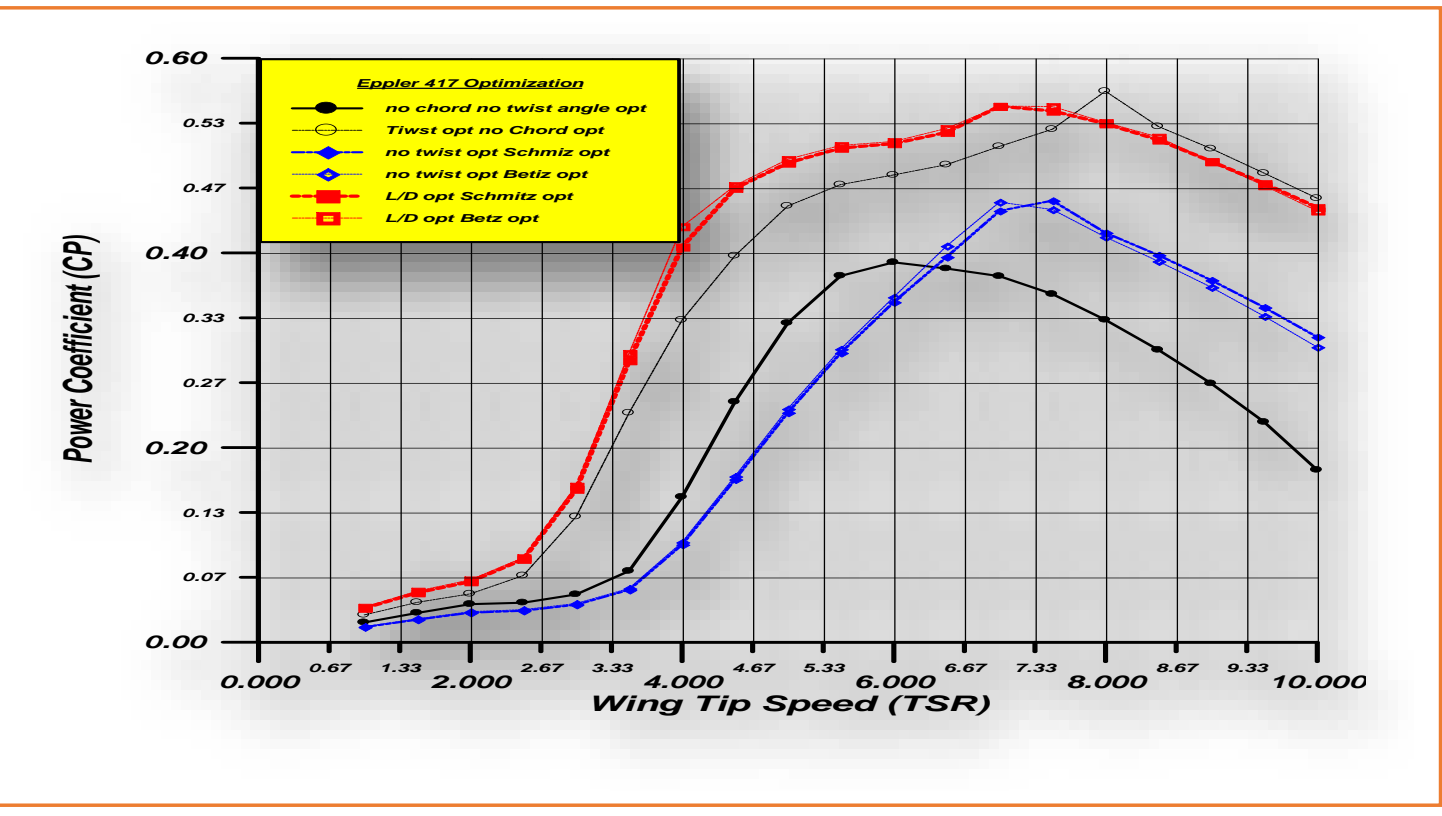

Figure (17) Lift to Drag Comparison Calculated CP and CFD calculation 
Journal of University of Babylon for Engineering Sciences, Vol. (26), No. (7): 2018.

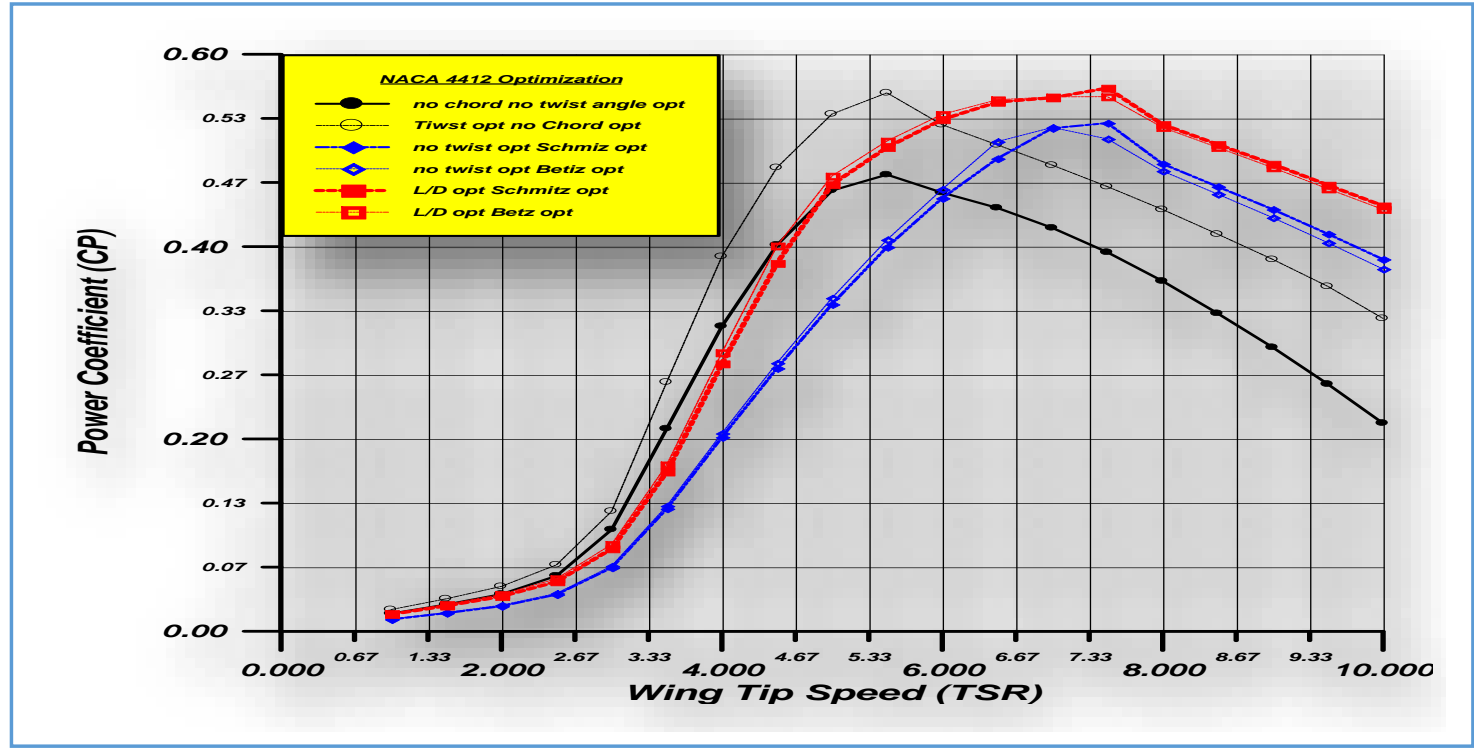

Figure (18) CP Coefficient Comparison for Different optimization Method/EPPLER 417

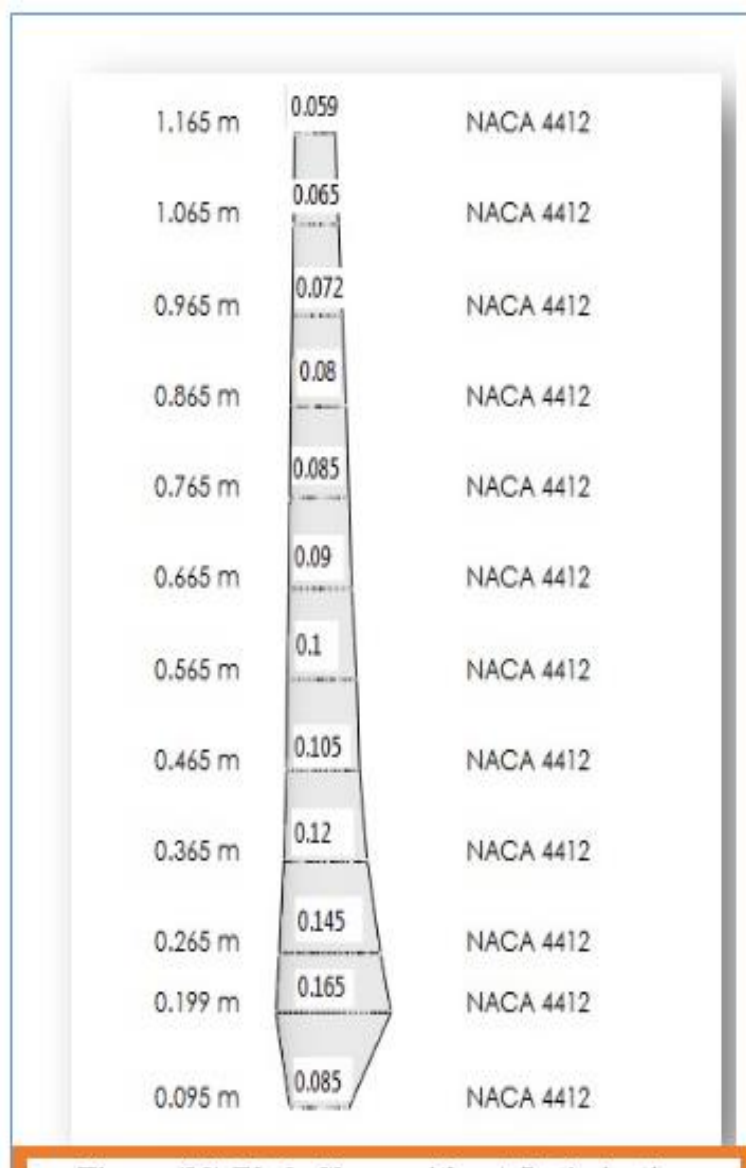

Figure (19) Blade Shape without Optimization

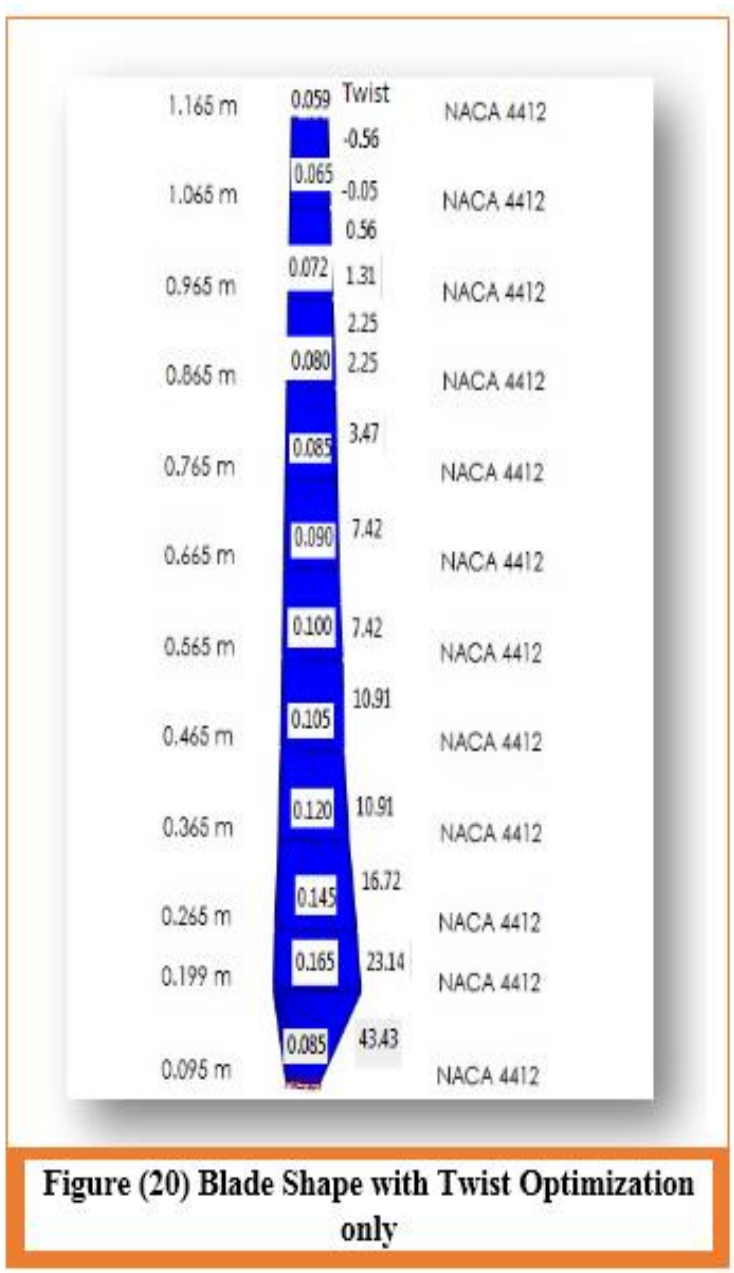


Journal of University of Babylon for Engineering Sciences, Vol. (26), No. (7): 2018.
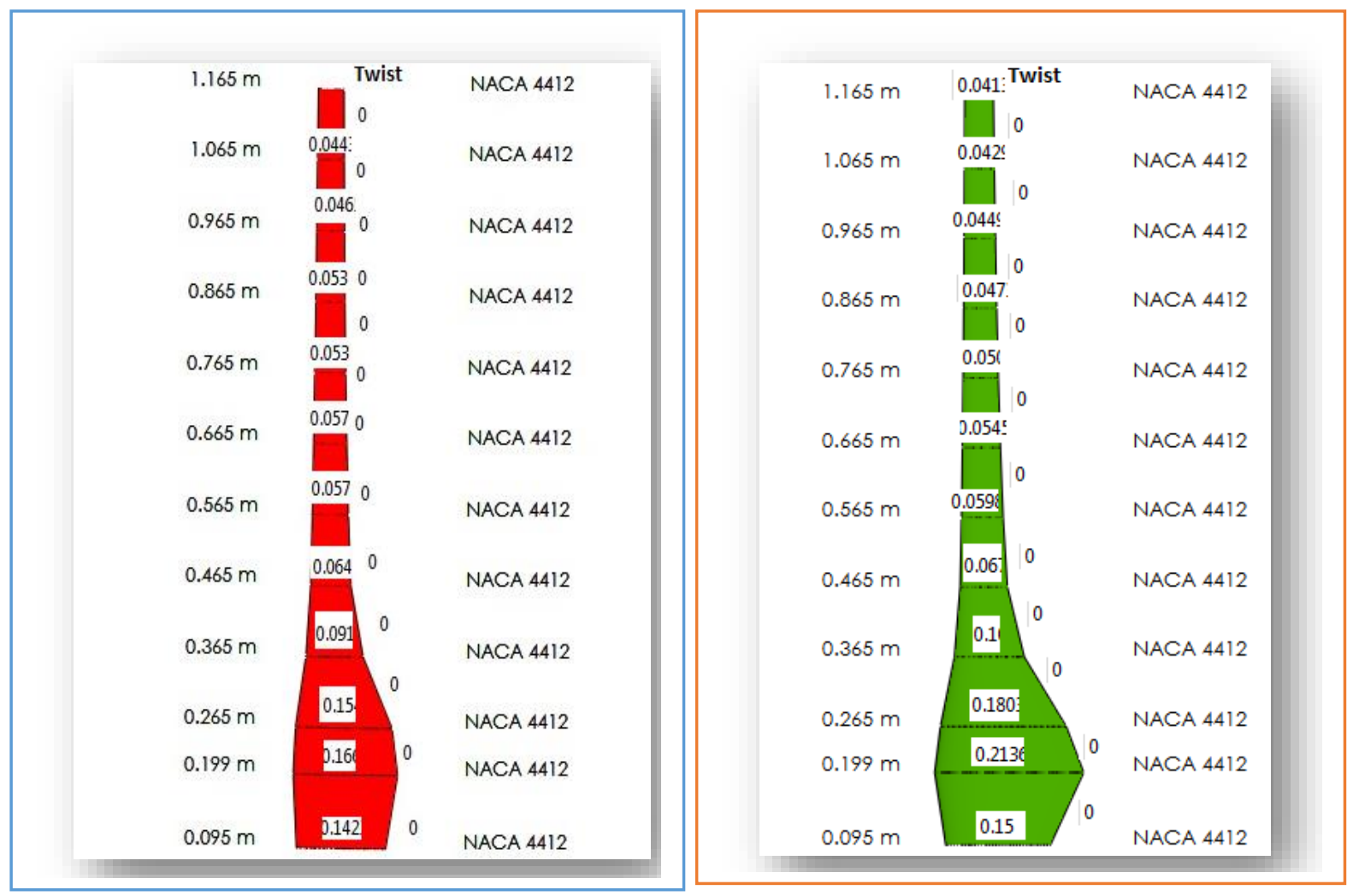

Figure (21) Blade Shape with Chord Optimization /shmiz

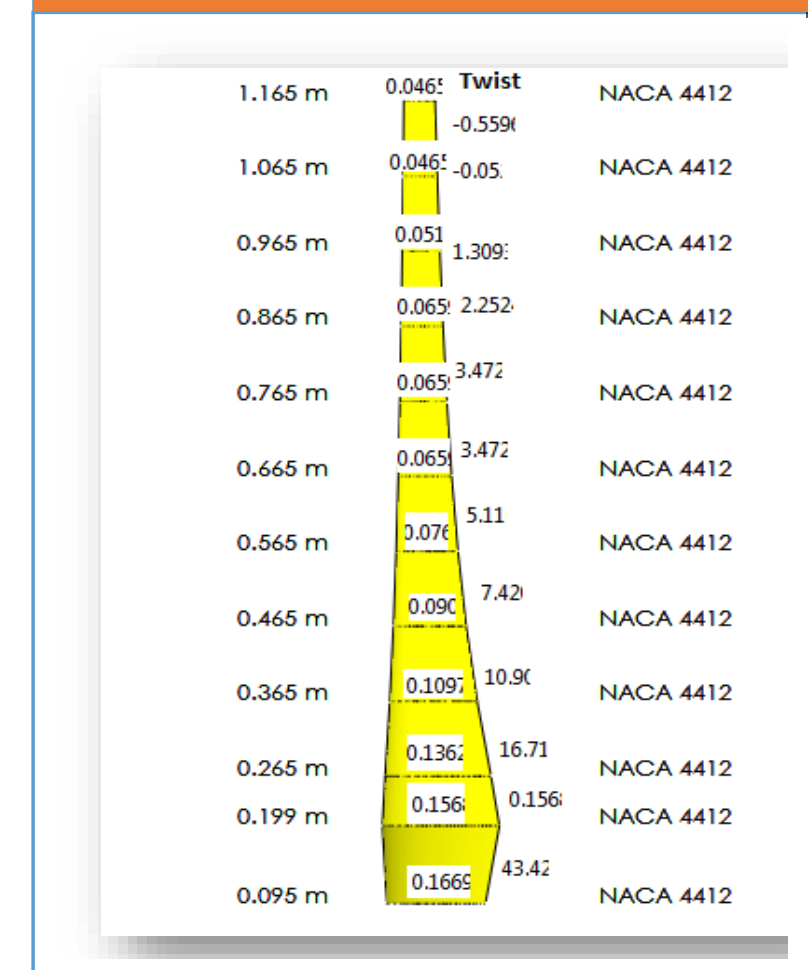

Figure (23) Blade with Twist and Chord Optimization /shmiz
Figure (22) Blade Shape with Chord Optimization /Bitz

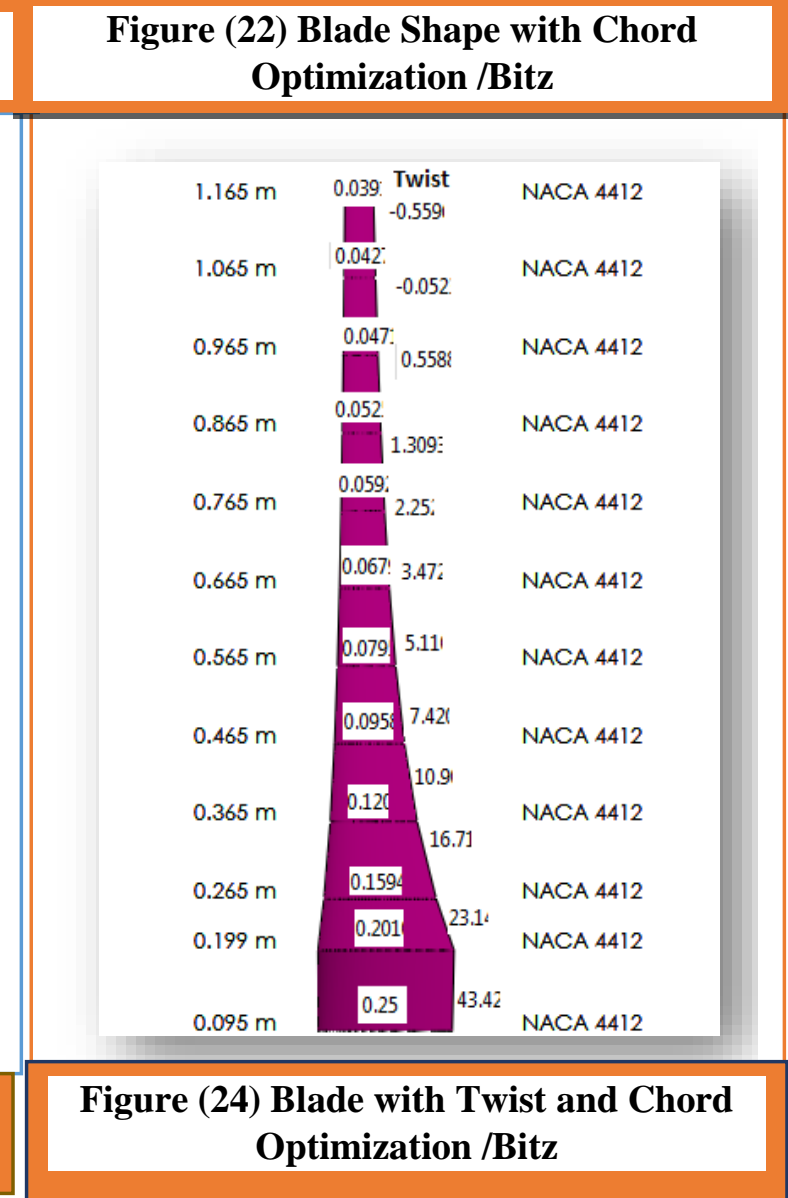


Journal of University of Babylon for Engineering Sciences, Vol. (26), No. (7): 2018.

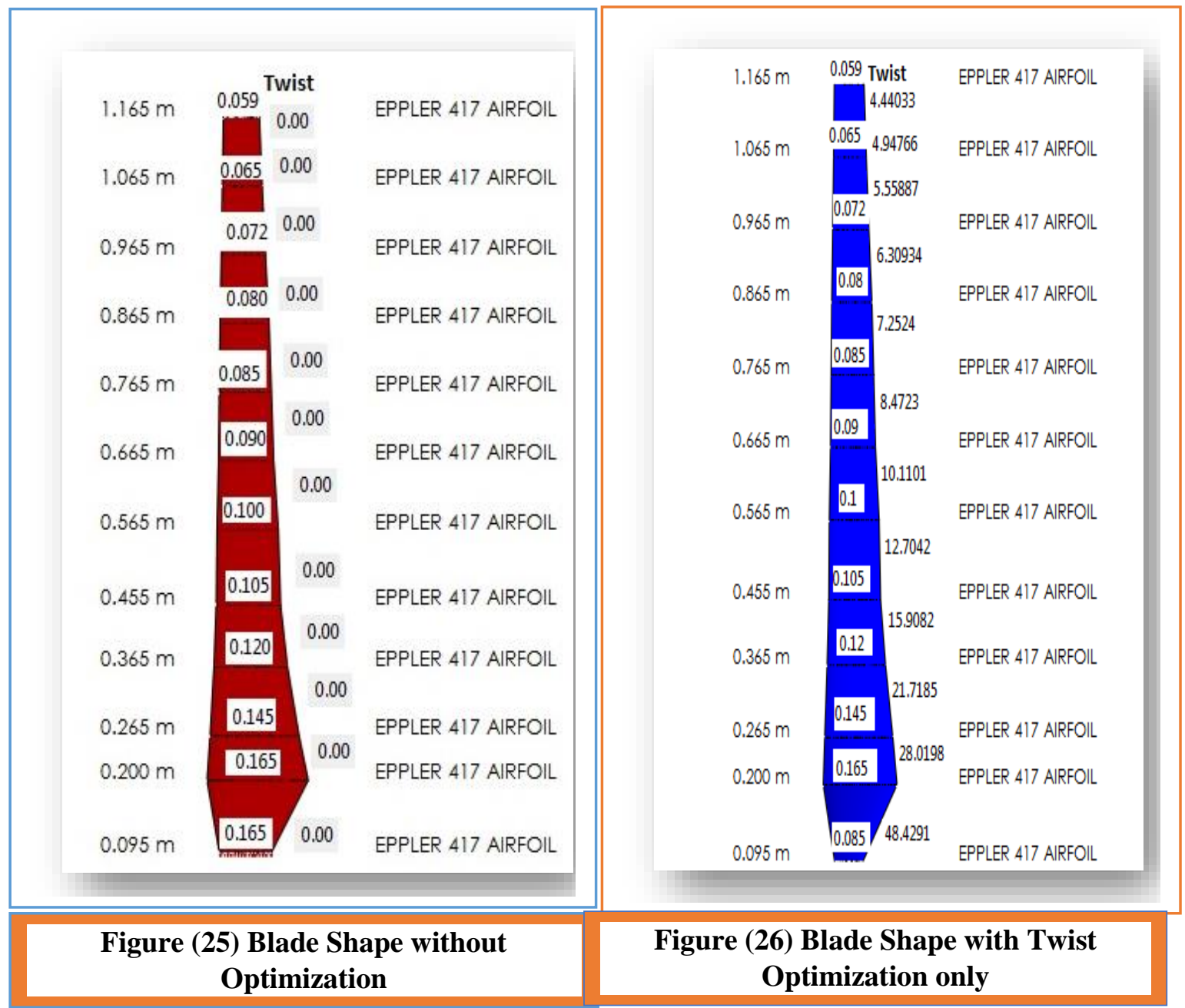


Journal of University of Babylon for Engineering Sciences, Vol. (26), No. (7): 2018.
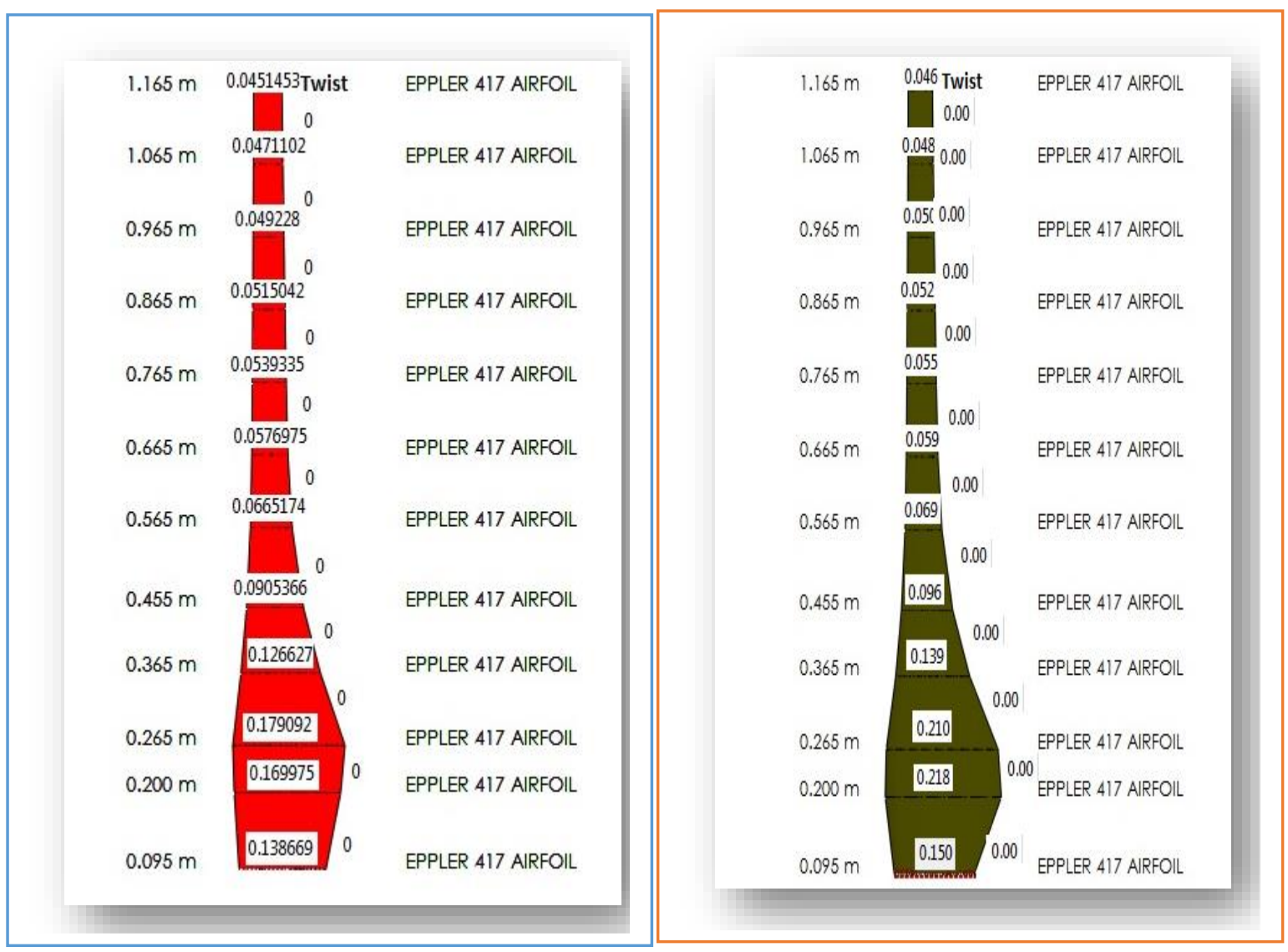

Figure (27) Blade Shape with Chord Optimization /shmiz

Figure (28) Blade Shape with Chord Optimization /Bitz 
Journal of University of Babylon for Engineering Sciences, Vol. (26), No. (7): 2018.

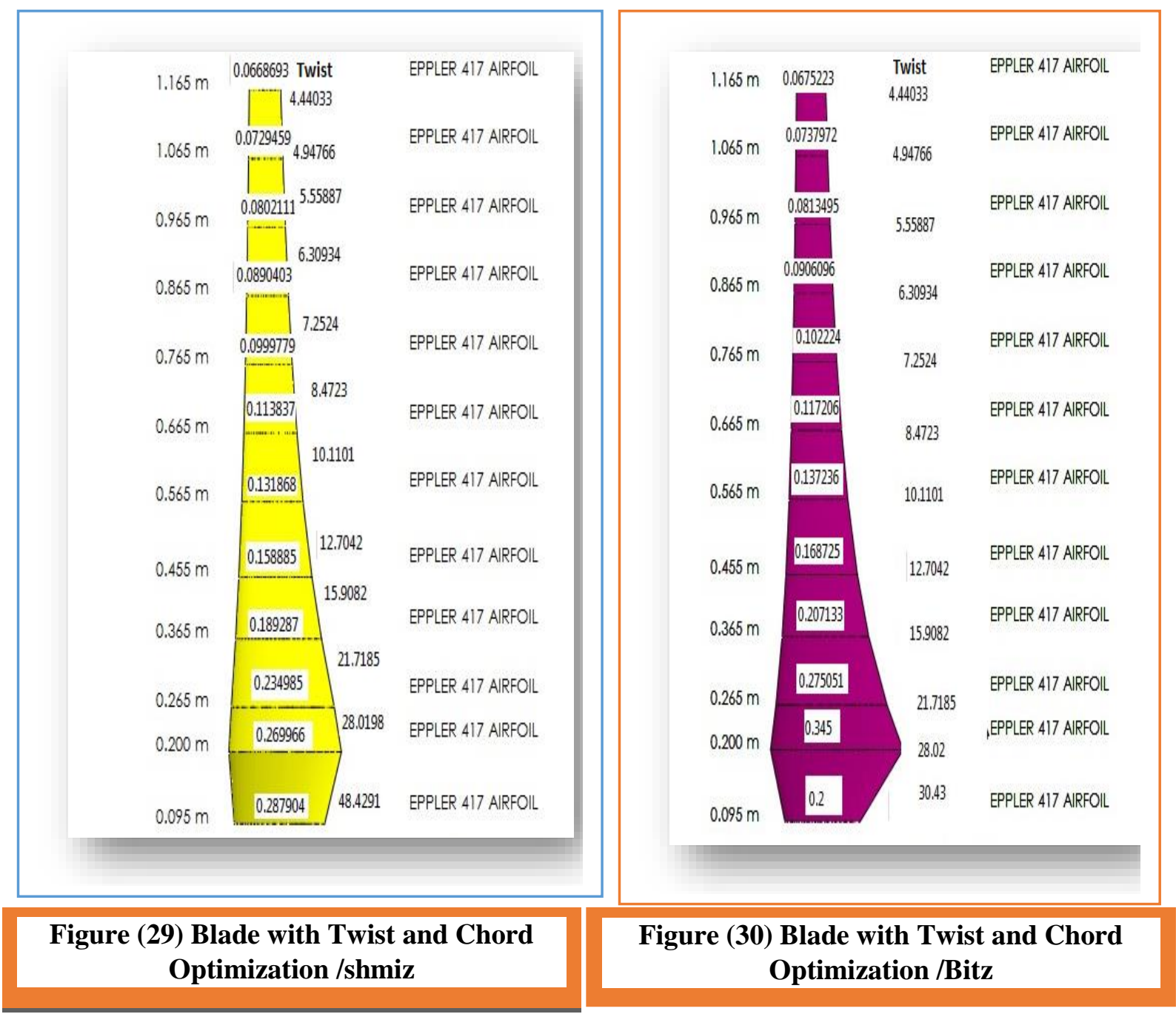

\section{Reference}

[1] Burton T., Sharpe D, Jenkins N., and Bossanyi E., Wind Energy Handbook. Jhon Wiley \& Sons, 2001.

[2] Jonkman J. M., modeling of the UAE wind turbine for refinement of the FAST AD.Technical Report NREL/TP-500-34755, National Renewable Energy Laboratory, 2003.

[3] Schepers J.G., Final report of IEA Annex XVIII: 'Enhanced field rotor aerodynamics database'. Technical Report ECN-C-02-016, Energy research Centre of The Netherlands, 2002.

[4] Bak, C. Gauna, M., Anderson, P. Buhl, T., Hansen, P., Clemens, K., and Moeller R., Wind tunnel test on wind turbine airfoil with adaptive trailing edge geometry, 45th AIAA Aerospace Sciences Meeting, and Exhibit, Reno, Nevada, 2007.

[5] Elsevier BV. Scopus Journal Analyzer, 2014, Available online: http://www.scopus.com/source/eval.url. 
Journal of University of Babylon for Engineering Sciences, Vol. (26), No. (7): 2018.

[6] Zheng Q, Rehman S, Alam M, Alhems L.M, Latin A., Decomposition of wind speed fluctuations at different time scales. J. Earth Syst. Sci. 126. [CrossRef] , 2017.

[7] Alam, M.M.; Rehman, S.; Al-Hadhrami, L.M.; Meyer, J.P., Extraction of the inherent nature of wind speed using wavelets and FFT. Energy Sustain. 22, 34-47. [CrossRef], Dev. 2014.

[8] Siddiqi, A.H.; Khan, S.; Rehman, S. Wind Speed Simulation Using Wavelets. Am. J. Appl. Sci. 2, 557-564, 2005.

[9] Rehman S.; Ali S.; Khan, S. Wind Farm Layout Design Using Cuckoo Search Algorithms. Appl. Artif. Intell. 30, 899-9224, 2016.

[10] Rehman S.; Khan S., Fuzzy Logic Based Multi-Criteria Wind Turbine Selection Strategy_A Case Study of Qassim, Saudi Arabia. Energies 9, 872, 2016. 
Journal of University of Babylon for Engineering Sciences, Vol. (26), No. (7): 2018.

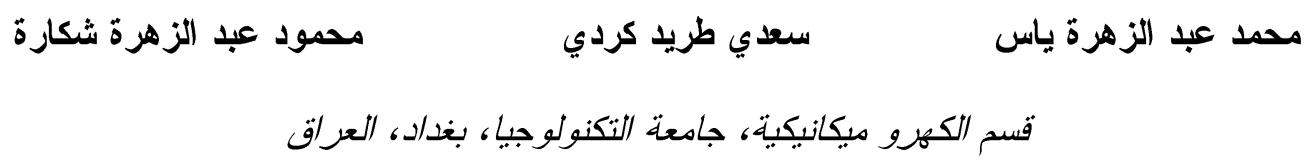

mahmoodsem@yahoo.com drsadijohary@gmail.com mohd.yass97@gmail.com

الخلاصة

البحث يقوم بتحليل وتحسين براميترات الخاصة بتورباين رياح افقي ذو اداء عالي المستوى مع تغير زاوية

خطوة الريشة لمقاطع مختلفة من الريش ذو مطيار غير متماتل نوع (NACA 4412) وكذلك لمطيار غير

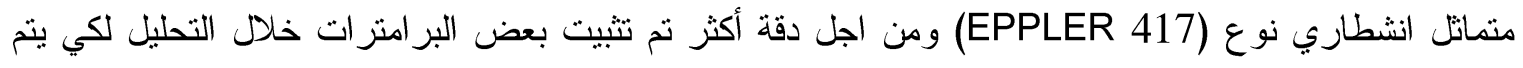

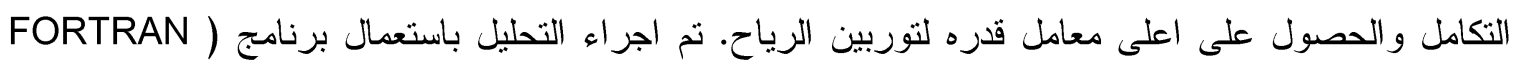

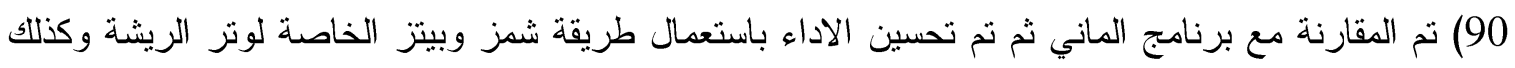

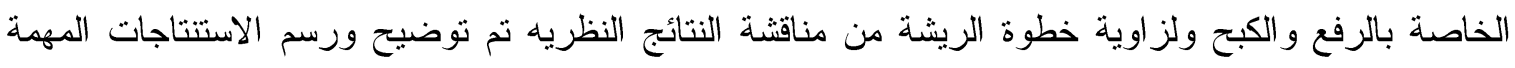

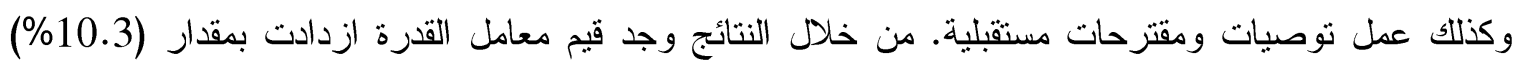

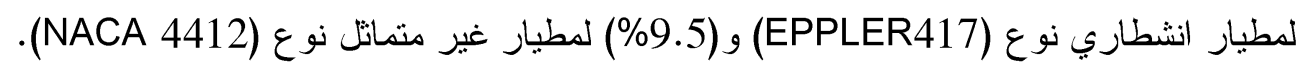
الكلمات المفتاحية: التصميم الأمتل، الخوارزميات، Betz Schmitz تحسين الرفع / السحب، طاقة الرياح،

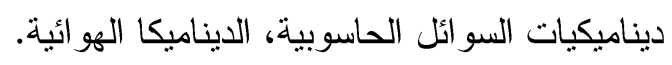

